\title{
Immune Regulation of Skin Wound Healing: Mechanisms and Novel Therapeutic Targets
}

\author{
Jacqueline Larouche ${ }^{1, \dagger}$ Sumit Sheoran, ${ }^{1, \dagger}$ Kenta Maruyama, \\ and Mikaël M. Martino ${ }^{1, *}$ \\ ${ }^{1}$ European Molecular Biology Laboratory Australia, Australian Regenerative Medicine Institute, \\ Monash University, Victoria, Australia. \\ ${ }^{2}$ WPI Immunology Frontier Research Center, Osaka University, Osaka, Japan. \\ ${ }^{\dagger}$ These authors contributed equally.
}

Significance: The immune system plays a central role in orchestrating the tissue healing process. Hence, controlling the immune system to promote tissue repair and regeneration is an attractive approach when designing regenerative strategies. This review discusses the pathophysiology of both acute and chronic wounds and possible strategies to control the immune system to accelerate chronic wound closure and promote skin regeneration (scar-less healing) of acute wounds.

Recent Advances: Recent studies have revealed the key roles of various immune cells and immune mediators in skin repair. Thus, immune components have been targeted to promote chronic wound repair or skin regeneration and several growth factors, cytokines, and biomaterials have shown promising results in animal models. However, these novel strategies are often struggling to meet efficacy standards in clinical trials, partly due to inadequate drug delivery systems and safety concerns.

Critical Issues: Excess inflammation is a major culprit in the dysregulation of normal wound healing, and further limiting inflammation effectively reduces scarring. However, current knowledge is insufficient to efficiently control inflammation and specific immune cells. This is further complicated by inadequate drug delivery methods.

Future Directions: Improving our understanding of the molecular pathways through which the immune system controls the wound healing process could facilitate the design of novel regenerative therapies. Additionally, better delivery systems may make current and future therapies more effective. To promote the entry of current regenerative strategies into clinical trials, more evidence on their safety, efficacy, and cost-effectiveness is also needed.

Keywords: immune system, chronic wounds, scarring, biomaterials, therapeutics, immunomodulation

\section{SCOPE AND SIGNIFICANCE}

CHRONIC SKIN WOUNDS and excessive scarring represent large and growing challenges to healthcare systems globally. For example, in 2009 , chronic wounds affected 6.5 million people in the United States, leading to US $\$ 25$ billion in annual treatment costs. ${ }^{1}$ With rising rates of obesity and diabetes, and an aging population, these numbers are projected to rise. ${ }^{1}$ Ineffectively treated chronic wounds can result in infection, sepsis, amputation, and, in extreme cases, death of the patient. Scarring can also have considerable

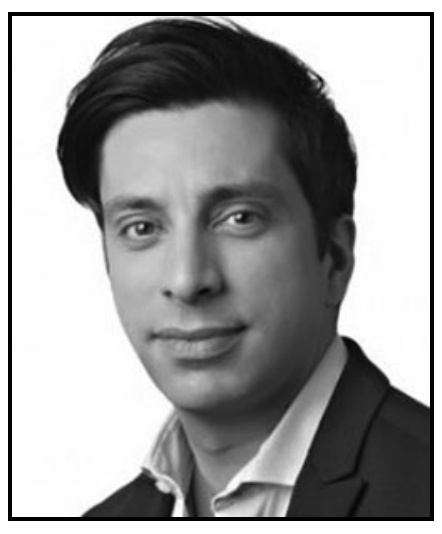

Mikaël M. Martino, PhD

Submitted for publication September 20, 2017. Accepted in revised form December 12, 2017

*Correspondence: European Molecular Biology Laboratory Australia, Australian Regenerative Medicine Institute, 15 Innovation Walk, Building 75, Level 1, Martino Lab, Victoria 3800, Australia (e-mail: mikael.martino@monash.edu). 
functional and physiological consequences. In 2004, an estimated 234 million surgeries were performed globally, corresponding to about one operation per 25 people. $^{2}$ These incisions result in a scar, each of which is very difficult to treat and impossible to prevent. Nonetheless, $\$ 12$ billion is spent annually in the United States to reduce scar size. ${ }^{1}$

The immune system is a key player throughout the wound healing process, actively participating to reestablish homeostasis following tissue injury via multiple mechanisms. ${ }^{3}$ For example, the immune response to tissue injury can mobilize tissue resident stem/progenitor cells, promote cell differentiation, extracellular matrix (ECM) deposition, and stimulate growth factor secretion to promote neoangiogenesis. Since these processes require a coordinated series of immune events, their disruption can lead to a variety of wound pathologies, including chronic wounds and scar formation. Chronic wounds are defined as wounds that fail to resolve after 1 month, often having persistent infections and microbial films. Clinically, they are classified as either venous or arterial ulcers, pressure sores, or diabetic ulcers (Fig. 1). ${ }^{4}$ Alternatively, dermal fibrosis results from increased deposition of ECM and hyper-proliferation of keratinocytes at the wound site. Keloids and hypertrophic (HT) scars both represent clinical pathologies of scarring, though even normal scar formation represents a failure of the dermal layer to regenerate postwounding (Fig. 2). ${ }^{4}$ Not surprisingly, chronic wounds and scarring represent nearly opposite extremes of dysregulated inflammation and im- mune response to dermal wounding. However, many of the mechanisms through which immune cells act to regulate the wound healing response are still unknown. Elucidating these pathways may aid in the development of novel regenerative strategies for promoting wound resolution and preventing scar formation.

\section{TRANSLATIONAL RELEVANCE}

There has been a recent growing interest in the development of immune-based therapies for both chronic wounds and scar prevention, mostly focusing on the delivery of growth factors, cytokines, and other immunomodulatory factors. However, translating these therapies for chronic wound resolution and scar prevention into the clinic has been particularly difficult, due to challenges related to delivery methods and safety. Most therapeutics currently rely on discrete, bolus doses, given via injections or applied topically to the wound site. Because of natural clearance, doses are given at supra-physiological levels to sustain drug presence throughout the wound healing process. This results in both safety concerns and poor long-term efficacy. Hence, developing new methods to effectively control and sustain drug release over longer periods of time is critical to the success of immune therapies.

\section{CLINICAL RELEVANCE}

Numerous immune-based therapies for both chronic wounds and scar prevention have entered clinical trials in the past decade. For example, macrophage-activating lipopeptide-2 (MALP-2)

\begin{tabular}{|l|l|l|}
\hline $\begin{array}{l}\text { Venous leg ulcer } \\
\text { - Common in elderly } \\
\text { - Result of chronic venous } \\
\text { hypertension } \\
\text { - Persistent inflammation } \\
\text { - Hemosiderin deposits } \\
\text { - Lipodermatosclerosis }\end{array}$ & $\begin{array}{l}\text { Arterial ulcer } \\
\text { - Reduced blood supply } \\
\text { - Ischemia, necrosis } \\
\text { - Little exudate } \\
\text { - Atrophic skin } \\
\text { - Common in diabetes } \\
\text { - Pain }\end{array}$ \\
\hline $\begin{array}{l}\text { Diabetic foot ulcer } \\
\text { - Common in diabetes }\end{array}$ & $\begin{array}{l}\text { Pressure sore } \\
\text { - Hyperglycemia } \\
\text { - Micro-/macroangiopathy } \\
\text { - Neuropathy } \\
\text { - Infection } \\
\text { - Foot deformities }\end{array}$ & $\begin{array}{l}\text { - Area of tissue necrosis } \\
\text { - Caused by prolonged } \\
\text { soft tissue compression } \\
\text { - Local ischemia, moisture }\end{array}$ \\
\hline
\end{tabular}

Figure 1. Clinical presentations of various chronic wound pathologies. Impaired wound healing cascade will lead to the development of nonhealing wound pathologies such as: (A) venous leg ulcer (B) arterial ulcer (C) diabetic foot ulcer (D) pressure sore. Reprinted with adaptation with permission from Ref. ${ }^{4}$ ๑AAAS Publishing Group. 


\begin{tabular}{|c|c|c|c|}
\hline Hypertrophic scar & A & B & Keloid \\
\hline $\begin{array}{l}\text { - Rapid growth } \\
\text { - Generally regress }<6 \text { months } \\
\text { - } \alpha \mathrm{SMA}^{+} \text {myofibroblasts } \\
\text { - Collagen fibers parallel to } \\
\text { skin surface } \\
\text { - Vertically oriented blood } \\
\text { vessels }\end{array}$ & & $0^{1}$ & $\begin{array}{l}\text { - Constant growth } \\
\text { - No spontaneous regression } \\
\text { - Extend beyond margins } \\
\text { of tissue damage } \\
\text { - Genetic predisposition } \\
\text { - Thick, haphazardly } \\
\text { oriented collagen bundles }\end{array}$ \\
\hline
\end{tabular}

Figure 2. Clinical examples of scarring pathologies. (A) Hypertrophic scar (B) Keloid. Reprinted with adaptation with permission from Ref. ${ }^{4}$ (CAAAS Publishing Group.

and platelet-rich plasma $(\mathrm{PRP})$ gels have reached clinical trials to resolve chronic wounds. ${ }^{5,6}$ In the case of scar prevention, transforming growth factor (TGF)- $\beta 3$, interleukin (IL)-10, mannose-6-phosphate (M6P), and nefopam have all reached clinical trials with varying levels of success. TGF- $\beta 3$ significantly decreased scar size in both phase I and II clinical trials, though complete regeneration was never achieved and it failed to meet efficacy standards in phase III. ${ }^{7,8}$ In the case of therapeutics for both chronic wounds and scar prevention, it is believed that improved delivery methods that permit sustained release may facilitate clinical effectiveness.

In this review, we describe the molecular pathophysiology of acute wounds and major etiologies that alter the normal wound healing cascade, leading to development of chronic wounds and scars. Then, we highlight the possible approaches to control the immune system using biomaterial and biologic-based strategies to promote chronic wound resolution and dermal regeneration (scar-less healing).

\section{BACKGROUND}

\section{Role of the immune system in acute skin wound healing}

Following injury, an inflammatory response is both normal and critical in restoring tissue homeostasis. Wound healing is typically divided into four phases: hemostasis, inflammation, proliferation, and remodeling. These phases result from a cascade of events, largely mediated by immune cells and signaling molecules (Fig. 3A). ${ }^{9}$ In response to cues from both the damaged ECM and tissue-resident cells, thrombocytes and immune cells accumulate at the wound site in a stepwise manner. Platelets are the first cells to arrive, at which point they help initiate the coagulation

\section{A Acute Wound}

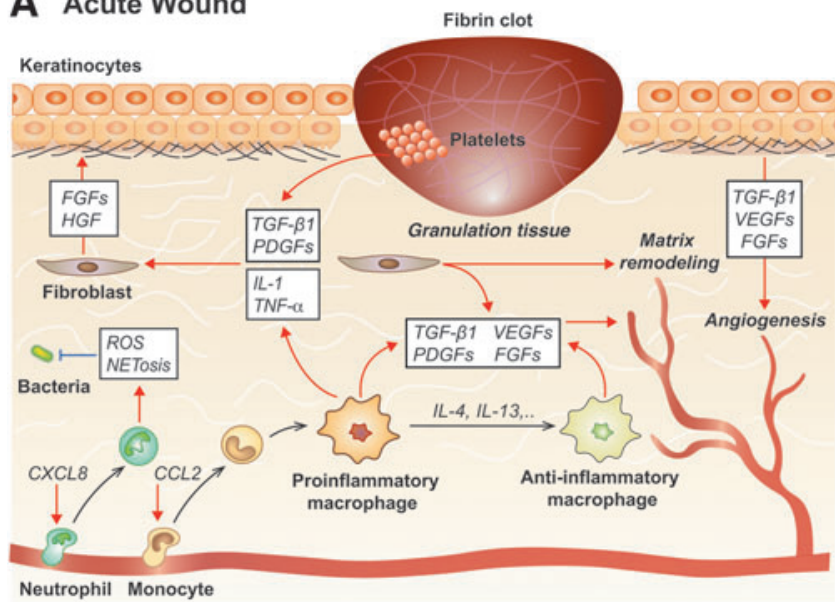

B Chronic Wound

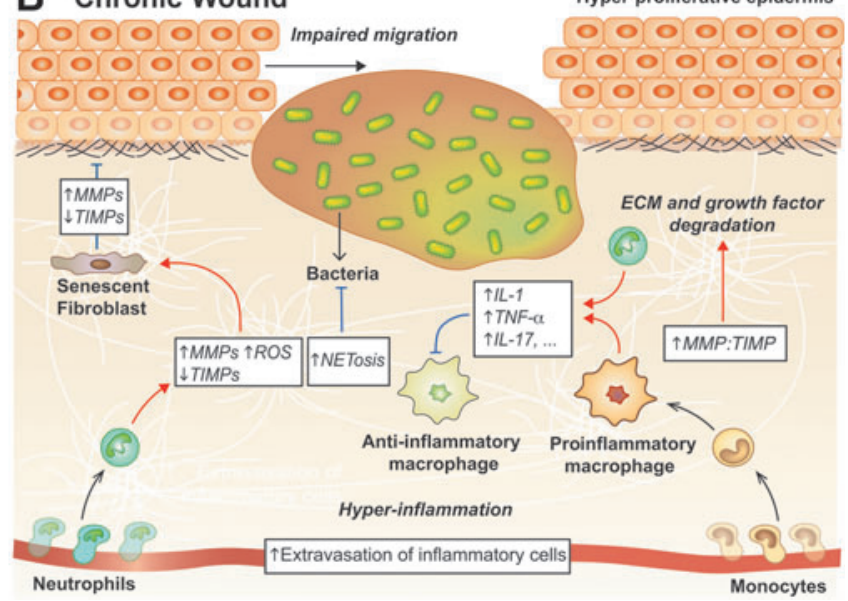

Figure 3. Overview of the immune mechanisms in acute and chronic wound healing. (A) Acute wound healing results from a well-coordinated series of events divided into four overlapping phases: hemostasis, inflammation, proliferation/matrix deposition, and tissue remodeling. Neutrophils and macrophages are particularly important in mediating this process, though T cells and platelets also play key roles. (B) High numbers of inflammatory cells and the formation of a biofilm preclude the restoration of tissue homeostasis in chronic wounds. Excess secretion of inflammatory mediators leads to growth factor and ECM degradation and prevents macrophage phenotype conversion, which creates a feed-forward loop preventing resolution. Black arrows indicate differentiation, blue arrows indicate inhibition and red arrows indicate induction. CXCL, C-X-C chemokine ligand; ECM, extracellular matrix; FGF, fibroblast growth factor; IL, interleukin; MMP, matrix metalloproteinase; NET, neutrophil extracellular trap; ROS, reactive oxygen species; TGF, transforming growth factor; TIMP, tissue inhibitor of matrix metalloproteinase; TNF, tumor necrosis factor. 
cascade to prevent further blood loss and provide a provisional ECM for further cell infiltration. Also, by secreting TGF- $\beta 1$ and platelet-derived growth factors (PDGFs), they play a critical role in the activation of fibroblasts and mesenchymal cells as well as in the recruitment and activation of neutrophils and macrophages. ${ }^{10-12}$ Unsurprisingly, platelet defects are correlated with impaired wound healing, and delivering autologous PRP improves wound resolution. ${ }^{13-16}$

Neutrophils are the first immune cells recruited into wounded tissue, and remain for about $24 \mathrm{~h}$ before undergoing apoptosis. ${ }^{17}$ They play a central role in both killing microbes and promoting wound healing. ${ }^{18}$ Neutrophils control invading pathogens by secreting a variety of antimicrobial substances-reactive oxygen species (ROS), antimicrobial peptides, and antimicrobial proteasesand by phagocytosing them with the help of neutrophil extracellular traps (NETs). ${ }^{19,20} \mathrm{Neu}-$ trophils also secrete various cytokines and growth factors, including IL-17 and vascular endothelial growth factor (VEGF). Cytokines and growth factors are both chemotactic for inflammatory cells, and promote the proliferation of fibroblasts, keratinocytes, and endothelial cells. ${ }^{18,21}$ Demonstrating the importance of neutrophils during wound healing, perturbation of neutrophil recruitment during the early phase of wound healing by knocking out C-X-C motif chemokine receptor 2 (CXCR2) in mice impairs wound healing. ${ }^{22}$ CXCR2 is an essential mediator of neutrophil chemotaxis via the release of numerous chemokine ligands, including C-X-C chemokine ligand (CXCL)-1, -5, and -8 , by keratinocytes at the wound site. ${ }^{23}$ However, CXCR2 knock-out mice also exhibit altered temporal patterns of monocyte infiltration, decreased secretion of IL- $1 \beta$, and reduced keratinocyte migration and proliferation, so impaired wound healing may be the result of numerous compounding factors. ${ }^{22}$ Another study found accelerated wound closure and reepithelialization in neutrophil-depleted mice, suggesting a relatively complex role of neutrophils during skin repair. ${ }^{24}$

Cytokines released by neutrophils during apoptosis are chemotactic for monocytes, which start to arrive 5 to $6 \mathrm{~h}$ postinjury. These monocytes differentiate into macrophages, which can remain for several weeks at the wound site. ${ }^{17}$ Monocytederived macrophages have been widely studied in the context of wound healing, and are often considered to be the most important immune cell type in this process. ${ }^{25,26}$ In addition to macrophages deriving from mobilized monocytes, there is a population of tissue-resident macrophages in most tissues that can proliferate upon injury. ${ }^{9}$ While, it has been demonstrated in a murine wound model that tissue-resident macrophages have little impact on the timing of the wound healing process or tissue integrity following resolution, ${ }^{27}$ their role in skin wound healing is still elusive.

Macrophages undergo phenotypic changes throughout the healing process, which helps transition the wound microenvironment from a proinflammatory into a pro-resolution state. ${ }^{9}$ The most commonly studied phenotypes are the proinflammatory - commonly referred to as "classically activated" or M1-and anti-inflammatoryreferred to as "alternatively activated" or M2macrophages. Indeed, this M1 and M2 classification originated from in vitro characterization, but a modified classification system has been recently proposed to link macrophage populations to activation pathways [e.g., M(IFN- $\gamma), \mathrm{M}(\mathrm{IL}-4)$, and so on].$^{28}$ Nevertheless, it is very difficult to know by which pathways macrophages have been activated in vivo. Hence, in this review, we refer to macrophage phenotypes based on their primary function in vivo ("anti-inflammatory," "proinflammatory," "profibrotic," etc.).

Many studies have confirmed that macrophages are critical for proper wound healing. ${ }^{29-32}$ Upon initial infiltration, proinflammatory macrophages (the so-called M1) remove cellular debris, damaged matrix, microbes, and neutrophils. They also secrete proinflammatory cytokines and growth factors (including IL-1, fibroblast growth factor [FGF]-2, PDGF, and VEGF), which mobilize more immune cells, and promote the proliferation of keratinocytes, fibroblasts, and epithelial cells. During the formation of new tissue, micro environmental cues trigger macrophages to transition into a functionally and phenotypically anti-inflammatory state (the so-called M2). At this point, they begin secreting anti-inflammatory cytokines, such as TGF- $\beta 1$, which promotes ECM synthesis and wound contraction. ${ }^{33}$ In the final stage of wound healing, antiinflammatory macrophages help reorganize the ECM along tension lines and phagocytose remaining debris. ${ }^{17}$ Demonstrating the importance of these immune cells, Lucas et al. depleted macrophages from mice at each phase of tissue repair. Early-stage macrophage depletion significantly reduced granulation tissue formation, impaired epithelialization, and resulted in decreased scar formation. Mid-stage macrophage depletion resulted in severe hemorrhage, while late-stage depletion did not significantly impact the outcome of the healing response. ${ }^{34}$ Moreover, anti-inflammatory macrophages play an 
important role in angiogenesis. They indirectly promote angiogenesis by degrading the ECM to create tunnels that guide endothelial proliferation and migration, and they release angiogenic factors, such as FGF and placental growth factor (PlGF). ${ }^{35}$

$\mathrm{T}$ lymphocytes ( $\mathrm{T}$ cells) are also critical in tissue remodeling and the resolution of inflammation. During the inflammatory phase of wound healing, macrophages secrete chemokines such as interferon gamma $(\mathrm{IFN}-\gamma)$ that attract $\mathrm{T}$ cells to the wound site. ${ }^{36,37}$ IFN- $\gamma$ also encourages $\mathrm{CD}^{+}$type $1 \mathrm{~T}$ helper $\left(\mathrm{T}_{\mathrm{H}} 1\right)$ polarization, which contributes to the initial proinflammatory wound microenvironment. ${ }^{38}$ Tissue resident $\gamma \delta \mathrm{T}$ cells also play a role in regulating skin wound healing. Indeed, $\gamma \delta \mathrm{T}$ cell-deficient mice show defects in skin development due to decreased keratinocyte proliferation. ${ }^{39}$ These immune cells most likely regulate keratinocyte proliferation and differentiation via their secretion of various growth factors, such as FGF-7, FGF-10, and insulin-like growth factor (IGF)-1. ${ }^{40}$ Importantly, there are significant differences between mouse and human $\gamma \delta \mathrm{T}$ cells, though studies exist that suggest a similar role of human $\gamma \delta \mathrm{T}$ cells in wound healing. ${ }^{41,42}$ For example, $\gamma \delta \mathrm{T}$ cells isolated from healthy human skin produce a constituent level of IGF-1, which increases threefold upon stimulation. Additionally, based on an in vitro skin organ culture model, T-cell receptor (TCR)-specific activation of human $\gamma \delta \mathrm{T}$ cells accelerates the rate of early wound closure. This increase in wound closure was dependent on IGF-1 secretion. ${ }^{42}$ Regulatory $\mathrm{T}$ cells (Tregs) also play a central role in maintaining skin homeostasis. ${ }^{43}$ They secrete arginase and anti-inflammatory cytokines (including IL-10 and TGF- $\beta 1$ ), which encourages anti-inflammatory macrophage polarization and suppresses the inflammatory response. ${ }^{44} \mathrm{~A}$ recent study using Foxp3-DTR transgenic mice (where Tregs are depleted following diphtheria toxin injection), showed that wound healing is slower in Treg depleted mice compared with wildtype controls. ${ }^{45}$ This clearly shows the importance of Tregs in cutaneous wound healing. Contrastingly, natural killer $\mathrm{T}$ cells have an inhibitory role on wound healing. Indeed, mouse studies have shown that depleting natural killer T cells increases wound closure rate. $^{46,47}$

As inflammation is resolved, the wound progresses into the final two stages of the wound healing process: matrix formation with angiogenesis and remodeling. This resolution is largely dependent upon macrophages, Tregs and $\mathrm{T}_{\mathrm{H}} 2$ cells. ${ }^{9}$ Anti-inflammatory macrophages are a prominent source of cytokines and growth factors that promote matrix deposition and angiogenesis, including
TGF- $\beta$, PDGF, FGF-2, IGF1, tumor necrosis factor (TNF)- $\alpha$, and VEGF. ${ }^{9}$ TGF- $\beta$ directly promotes ECM synthesis by stimulating mesenchymal cells to differentiate into myofibroblasts. Furthermore, TGF- $\beta$ and PDGF trigger fibroblasts and myofibroblasts to produce new ECM. ${ }^{9} \mathrm{~T}_{\mathrm{H}} 2$ cells and Tregs also contribute to matrix formation by secreting TGF- $\beta 1$, IL-4, -5, -13, and -21 , which play a distinct role in fibrinogenesis, encouraging anti-inflammatory macrophage polarization, and suppressing other inflammatory cell types. ${ }^{3,9,48}$ For example, studies have suggested that IL- 4 is almost twice as potent as TGF- $\beta$ at stimulating collagen synthesis. ${ }^{49}$

During the final phase of wound healing, antifibrotic macrophages release numerous matrix metalloproteinases (MMPs) (including MMP-2, -12 , and -19) and trigger the production of type VIII collagen critical for improving local tissue integrity. ${ }^{9}$ The result is a decrease in cell proliferation and protein synthesis, and an ECM that is remodeled into larger fibrils oriented along tension lines. Eventually, most endothelial cells, macrophages, and myofibroblasts either exit the wound or undergo apoptosis, and recently formed capillaries begin to regress, potentially due to reduced nutrient requirements. ${ }^{9}$ Depending on the size of the initial injury, this entire process usually results in a small scar. ${ }^{4}$

\section{DISCUSSION OF FINDINGS AND RELEVANT LITERATURE}

\section{Role of the immune system}

in chronic wounds

While the wound healing cascade is well coordinated in acute wound healing, chronic wounds fail to progress beyond the inflammatory phase (Table 1), which precludes proliferation, matrix deposition, and ultimately, wound resolution. ${ }^{50,51}$ Indeed, many studies have shown that there is an imbalance between pro- and anti-inflammatory signals in chronic wounds, which disturbs the microenvironment and hampers the wound healing process. ${ }^{52,53}$

Role of neutrophils in chronic wounds. While neutrophils play a role in reestablishing tissue homeostasis through pathogen phagocytosis and macrophage recruitment, excessive neutrophil activity can contribute to the development of nonhealing wounds. ${ }^{10,21}$ For instance, excess neutrophils at the wound site lead to an overproduction of ROS, causing ECM and cell membrane damage, and resulting in premature cell senescence (Fig. 3B). ${ }^{19,54}$ Not only do ROS directly damage the ECM, but they also activate proteases (MMPs and serine proteases) and 
Table 1. Comparison of the immune microenvironment between acute and chronic wounds

\begin{tabular}{|c|c|c|}
\hline Components & Acute Wounds & Chronic Wounds \\
\hline Inflammation & Controlled & Increased \\
\hline Neutrophils & $\begin{array}{l}\text { Present only during early phase } \\
\text { Controlled NETosis }\end{array}$ & $\begin{array}{l}\text { Prolonged presence } \\
\text { Increased NETosis }\end{array}$ \\
\hline Macrophages & $\begin{array}{l}\text { Polarization transition from } \\
\text { pro- to anti- inflammatory } \\
\text { phenotype }\end{array}$ & Impaired polarization \\
\hline Inflammatory cytokines & Low level & Increased level \\
\hline $\begin{array}{l}\text { Anti-inflammatory } \\
\text { cytokines }\end{array}$ & High level & Low level \\
\hline Granulation tissue & Present & Low amount \\
\hline MMPs & Low level & High level \\
\hline TIMPs & Normal level & $\begin{array}{l}\text { Low level when } \\
\text { compared to } \\
\text { increased MMPs }\end{array}$ \\
\hline Fibrosis & Low level & Increased \\
\hline Growth factors/cytokines & Normal degradation rate & $\begin{array}{l}\text { Increased degradation } \\
\text { rate }\end{array}$ \\
\hline
\end{tabular}

MMP, matrix metalloproteinase; NET, neutrophil extracellular trap; TIMP, tissue inhibitor of matrix metalloproteinase.

inactivate protease inhibitors. ${ }^{55-57}$ Unsurprisingly, this results in increased proteolysis, further exacerbating ECM degradation. ${ }^{58-61}$ In addition, proteases released by neutrophils are capable of degrading key wound healing growth factors, including PDGF-BB and TGF- $\beta 1$ (Fig. 3B). ${ }^{10,62}$ Finally, although the mechanism is not fully understood, it has been shown that excess NETosis impairs wound resolution in both mice and humans. ${ }^{63-66}$

Because neutrophils are recruited to wound sites in such large numbers and exacerbate the proinflammatory microenvironment through toxic compounds and cytokine secretion, their efferocytosis is critical to inflammation resolution. In fact, dysregulated neutrophil apoptosis is likely a key contributor to the nonhealing state of chronic wounds. Chronic wounds in diabetic mice have increased numbers of apoptotic cells, most of which are neutrophils, resulting in a prolonged inflammatory state. ${ }^{67}$ Interestingly, neutrophils isolated from chronic diabetic mouse wounds undergo less apoptosis in response to $S$. aureus infection. This also results in sustained secretion of proinflammatory cytokines, including TNF- $\alpha .{ }^{68}$ The discrepancy potentially results from an overall increase in neutrophil recruitment to diabetic wounds or from the lack of bacterial infection in the first study. However, in both cases, dysregulated neutrophil apoptosis contributed to the chronic wound state.

Role of macrophages in chronic wounds. Increased macrophage infiltrate at the wound site can also perturb the normal wound healing process, contributing to the development of nonhealing wounds. ${ }^{69}$ Moreover, macrophage conversion from a proinflammatory to an anti-inflammatory phenotype is critical to wound resolution. ${ }^{70}$ If this phenotypic conversion does not occur or reach completion, it may lead to the development of chronic wounds (Fig. 3B). For example, using iron to induce an incomplete macrophage phenotypic switch impairs healing in both humans and mice. ${ }^{71}$ In these studies, $80 \%$ of macrophages at the wound margins had a proinflammatory phenotype, contributing to the persistence of the wounds. ${ }^{71}$ Other studies in diabetic mouse models have also shown that when macrophages do not undergo the appropriate phenotypic conversion, it leads to a reduction in key growth factors, such as TGF- $\beta 1$, VEGF, and IGF-1, which are necessary for the progression into the proliferation phase. ${ }^{72}$ Proinflammatory macrophages also secrete inflammatory mediators, such as TNF- $\alpha$, IL-17 and IL-1 $\beta$, ROS, and inducible nitric oxide synthase (iNOS), which have negative effects on the wound microenvironment at high concentrations. ${ }^{73}$ For instance, surplus TNF- $\alpha$ leads to increased secretion of MMP-1 and MMP-3 and decreased tissue inhibitor of matrix metalloproteinase (TIMP)-1 secretion, which directly contributes to wound chronicity through excess ECM proteolysis. ${ }^{74}$ Similarly, excess ROS disturb the oxidant/antioxidant balance. Not only does this enhance the signaling pathways that regulate the secretion of proinflammatory cytokines/chemokines (IL-1, IL-6, and TNF- $\alpha$ ) and MMPs, but it is also implicated in premature fibroblast senescence. ${ }^{75,76}$ This further contributes to wound chronicity as senescent fibroblasts produce elevated levels of proteases (including MMPs 2, 3, and 9), and fewer protease inhibitors. ${ }^{4,76}$ Altogether, changes in macrophage polarization are highly regulated in acute wound healing, and disruptions contribute to the development of wound chronicity.

Beyond secreting cytokines and growth factors to mediate wound healing, macrophages play a critical role in phagocytosing apoptotic cells and other debris in the wound bed. As previously mentioned, efficient efferocytosis is especially critical in the context of chronic wounds due to increased infiltration and apoptosis of neutrophils. However, in chronic wounds, macrophages exhibit a reduced phagocytic capacity, exacerbating the apoptotic cell burden. ${ }^{67}$ In addition, unsuccessful efferocytosis results in a higher ratio of pro:anti-inflammatory cytokines, further compromising resolution of diabetic wounds. ${ }^{67}$ 
Role of adaptive immune cells in chronic wounds. Compared to our understanding of the role of the innate immune system in exacerbating nonhealing wounds, little is known about the role of the adaptive immune system. In a human ex vivo model, it has been shown that a higher number of Langerhans cells (LCs) (a dendritic cell subtype present in early-phase wound healing) is present in healing diabetic foot ulcers (DFUs) compared with nonhealing DFUs. ${ }^{77}$ One of the main roles of LCs following tissue injury is activating and recruiting $\mathrm{T}$ cells. ${ }^{77}$ Interestingly, there are also fewer $\mathrm{T}$ lymphocytes in chronic wounds, and those that are present exhibit an unresponsive, functionally impaired state. ${ }^{39,42}$ Indeed, $\gamma \delta$ and $\alpha \beta$ T cells isolated from human chronic wounds fail to secrete IGF-1 and IL-2, even following stimulation with phorbol myristate acetate and ionomycin. ${ }^{42}$ Nevertheless, while chronic wounds have prolonged infiltration and different ratios of CD4 and CD8 T cells compared with acute wounds, depleting mice of CD4 and CD8 T cells does not appear to affect wound closure rates. ${ }^{69,78}$

\section{Bacterial colonization in chronic wounds.} Bacterial overload is another major factor precluding the resolution of chronic wounds. In certain microenvironments, including those in chronic wounds, bacteria thrive as complex surfaceattached communities enclosed in an ECM composed of hydrated polymers and debris. This is known as a biofilm. Interestingly, biofilms are not only immune to destruction by the host's immune system, but they also likely manipulate and depend upon the inflammatory response as a source of sustained nutrients. ${ }^{79,80}$ Bacterial pathogens in the biofilm express a range of virulence factors that upregulate the levels of proinflammatory cytokines, ROS and MMPs, while diminishing levels of TIMPs and growth factors. This creates a steady state of hyper-inflammation that is outside of the host's control, contributing to the etiology of chronic wounds and making resolution challenging. Biofilms further impair wound healing by perturbing the tight junctions between epithelial cells. Tight junctions create a fluid-impermeable barrier by joining the cytoskeletons of adjacent epithelial cells. Because of this, they are critical to skin's protective function. Biofilms interfere with this barrier partly by causing the downregulation of proteins responsible for creating the tight junctions, including zona occludens-1 and zona occludens-2. ${ }^{81}$ Hence, even though the biofilm-infected wound may eventually appear closed, functionally compromised, leaky skin can lead to future infections and wound healing complications. ${ }^{81}$

\section{Regulation of skin scarring by the immune system}

Scar formation begins in the third phase of wound healing, when fibroblasts, keratinocytes, and epithelial cells are recruited into the site of injury. At this point, fibroblasts differentiate into myofibroblasts, which secrete and assemble new ECM. ${ }^{48}$ This new ECM is later remodeled to form scar tissue. Not only does the secretion of cytokines by leukocytes play a direct role in the initial recruitment of fibroblasts, but the general inflammatory response also plays a key role in mediating future scar development (Fig. 4). This is most evident in the differences between fetal and adult wound healing. In the first two trimesters of human development, fetuses heal dermal wounds without a scar. This phenomenon is likely dependent upon the absence of immune cells, since the transition into the third trimester is characterized by the development of myeloid lineages and significant scarring following injury in both humans and mice. ${ }^{82}$ Wild-type mice undergo a similar transition, evidenced by scarless wound healing in embryonic day 15 (E15) mice and scar formation in embryonic day 18 (E18) mice. ${ }^{78,82}$ Early studies found similar scarless wound healing in neonatal PU.1 null mice, which lack neutrophils, macrophages, and mast cells. They also have reduced mRNA levels of TGF- $\beta 1$ and PDGF, which act as important profibrotic mediators stimulating myofibroblast differentiation and ECM synthesis. Interestingly, Tcell-deficient athymic nude-nu mice also heal with minimal scarring. ${ }^{82-83}$

Role of neutrophils in skin scarring. Potentially because they only participate in the earliest stages of wound healing, few studies have looked at the role of neutrophils in dermal scarring and they are believed to have a negligible long-term impact. Nonetheless, it is interesting to note that neutrophils are absent from scarless fetal wounds, there is an $80 \%$ reduction of neutrophil circulation in $\mathrm{Ac}$ omys mice (which heal full-thickness excisional skin wounds with complete regeneration of dermal components and without scarring) compared with Mus mice that heal with a scar, and there is a significant reduction in neutrophil recruitment to wounds in the oral mucosa, which also heals rapidly and with minimal scarring. ${ }^{78,84}$

Role of macrophages in skin scarring. The role of macrophages in dermal scarring has been extensively studied, and shown to change throughout 

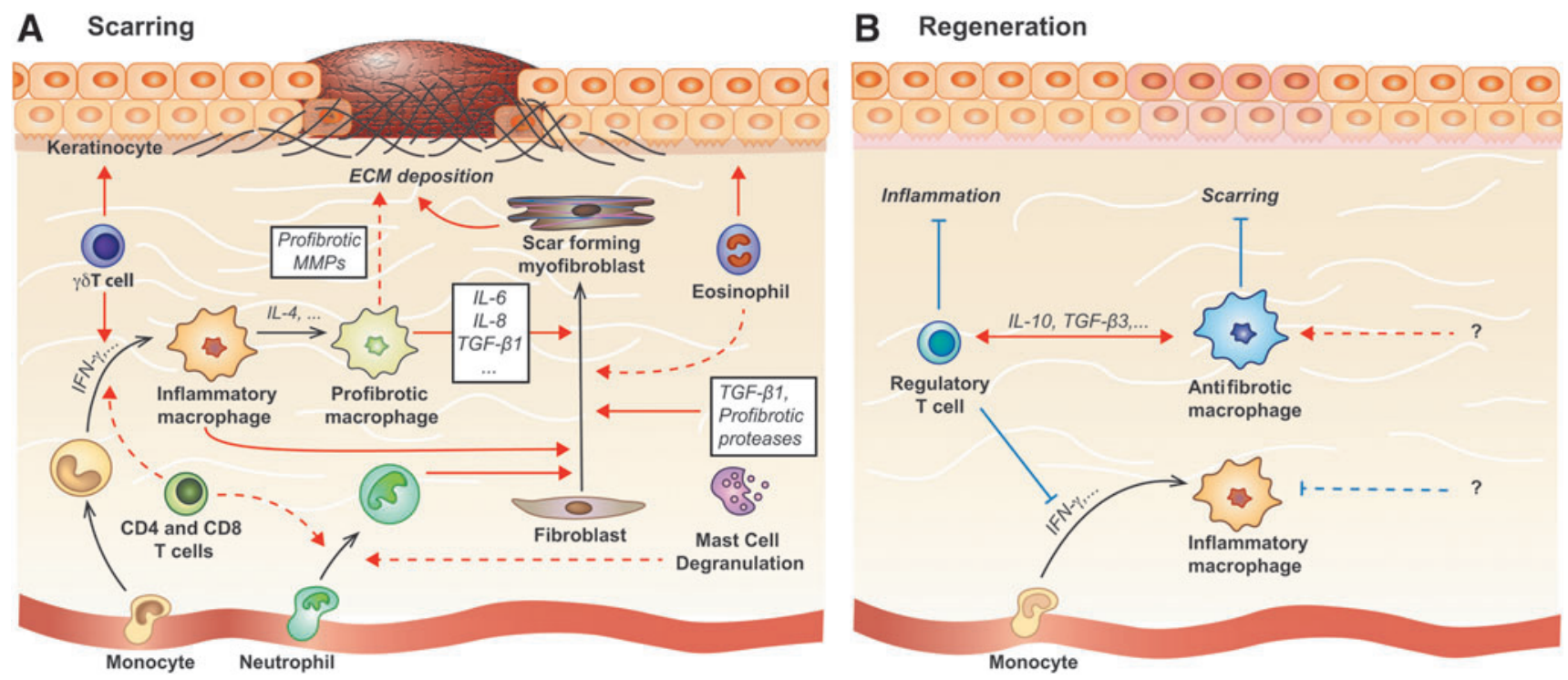

Figure 4. Molecular and cellular mechanisms involved in scar formation and dermal regeneration. (A) Immune cells act along numerous, redundant pathways to promote excess ECM deposition and hyperproliferation of keratinocytes, leading to scar formation. Key immune cell types involved in pathologic scar formation include macrophages, mast cells, neutrophils, eosinophils, and T cells. (B) Dermal regeneration is improved by generally decreasing innate and adaptive immune cell recruitment and activation, and encouraging antifibrotic macrophage polarization (e.g. via IL-10). Pathways that induce antifibrotic macrophage polarization in vivo are still very elusive, though research on other tissues suggests that Tregs may help promote antifibrotic macrophage polarization and suppress proinflammatory immune responses. Black arrows indicate differentiation, blue arrows indicate inhibition and red arrows indicate induction. IFN, interferon; Treg, regulatory T cells.

the stages of wound healing. ${ }^{25}$ Monocytes are the primary cells that secrete IL-1, which increases collagen synthesis, and promotes fibroblast and keratinocyte proliferation. ${ }^{23}$ Ablating or depleting macrophages during the acute and subacute phases of repair results in slower wound closure, epithelialization, and granulation tissue formation, but significantly reduced scarring. ${ }^{25,34,85} \mathrm{Si}$ milarly, reducing macrophage migration, adhesion, and their ability to produce TGF- $\beta 1$ by diminishing $\beta$-catenin levels results in slower wound repair but less scarring. ${ }^{86}$ If macrophage inhibition or ablation is discontinued, wound closure rates are rescued by their infiltration in the later stages of wound repair without affecting scar formation or morphology. ${ }^{85}$ Alternatively, only depleting macrophages in the late stage wound healing has no effect on scar morphology compared to control mice. ${ }^{25,34}$ Furthermore, a study by Dardenne et al. showed that wounds treated with high mobility group box-1 (HMGB-1), an alarmin, have increased scarring. These wounds showed a significant increase in macrophages $48 \mathrm{~h}$ postinjury and no differences in neutrophil infiltration or mast cell numbers or degranulation. ${ }^{87}$ Contrarily, a study examining HT and normotrophic (NT) scars on human subjects found delayed and prolonged macrophage infiltration in HT scars compared with NT scars, suggesting an important role for initial macrophage infiltration rather than later-stage macrophage presence in reducing fibrosis. ${ }^{88}$

It is possible that changes in macrophage polarization are critical in determining the varying role of macrophages in wound healing. Indeed, in muscle remodeling, increases in the antiinflammatory population and higher ratios of anti- to proinflammatory macrophages within the remodeling site at 14 days postinjury were associated with reduced scarring. ${ }^{89}$ During early stage wound healing, there is a mixed pro/ anti-inflammatory activation phenotype. This transitions to an anti-inflammatory macrophage polarization in late stage wound healing characterized by an upregulation of IL- $10{ }^{25}$ Since wound associated macrophages are the main sustained source of TGF- $\beta \mathrm{s}(1,2$, and 3$)$ and extensively secrete MMPs to activate TGF- $\beta$, differences in TGF- $\beta$ and MMP secretion between classically and alternatively activated macrophages could account for the time-specific role of macrophages. ${ }^{85,90}$ For example, IL-4, a cytokine that promotes profibrotic macrophage polarization, was significantly downregulated in Acomys, which heal without a scar, compared to Mus. Macrophages polarized via IL-4 (M(IL-4)) are known to secrete and activate TGF- $\beta 1$, so their absence likely reduces collagen deposition. ${ }^{91}$ Broek et al. also found increased and prolonged ex- 
pression of anti-inflammatory macrophages in HT scar compared with NT scar, and decreases in inflammatory gene expression (including IL-10) over a 52 -week period. ${ }^{88}$ Hence, it is possible that the macrophages present were remaining in the profibrotic polarization state rather than transitioning to an antifibrotic M(IL-10)-like polarization, leading to the HT scar development.

Role of mast cells in skin scarring. The final immune cell subtype about which there exists substantial literature is the mast cell, though the effect of mast cells in scar formation remains somewhat under debate. ${ }^{92}$ Mast cells are tissue resident and become activated following tissue injury, releasing granules into the extracellular space. They secrete TGF- $\beta 1$, as well as other proteases that promote fibrotic responses in fibroblasts and collagen fibril formation. ${ }^{92}$ Mast cells also form gap junctions with fibroblasts to stimulate myofibroblast differentiation, proliferation, and ECM contraction. ${ }^{93-96}$ It has been found that mice treated with disodium cromoglycate (DSCG) to inhibit mast cell activation results in a reduced scar width, higher fibrillar density, and collagen fibers that were oriented more similarly to normal tissue compared to controls. DSCG treated mice also showed decreased neutrophil recruitment and fewer proinflammatory cytokines. ${ }^{97}$ There are significantly less dermal mast cells in second trimester fetal wounds compared to third trimester wounds, and almost no degranulation. Interestingly, injecting mast cell lysates into E15 wounds resulted in scarring, and wounds in E18 mast cell-deficient mice healed with significantly less scarring than wild-type littermates. ${ }^{98}$ There is also less mast cell degranulation in oral mucosal wounds compared with cutaneous wounds, and higher mast cell numbers in HT scars compared with normal scars. ${ }^{82,92}$ Contrarily, a study by Willenborg et al. showed genetic ablation of mast cells does not alter the amount of scar tissue, or the infiltration of leukocytes into the injury site. ${ }^{99}$ Further research into the role of mast cells in scar formation is needed to resolve this discrepancy.

Role of $T$ cells in skin scarring. Though they are known to play a role in immune cell recruitment and cytokine expression, the role of $\mathrm{T}$ cells on scar development is unclear. Recently, Nosbaum et al. found that mice depleted of Tregs have significantly slower wound closure and increased granulation tissue compared to wild-type mice partly due to their suppression of IFN- $\gamma$, which reduces the recruitment of proinflammatory macrophages. ${ }^{45}$ An earlier study showed that CD4-deficient mice had reduced neutrophil recruitment to the wound site, whereas CD8-deficient mice had less neutrophils and macrophages. The changes in cytokine expression also differ according to whether mice are CD4 deficient or CD8 deficient. ${ }^{100}$ While there are many subsets of CD4 lymphocytes, two main types are $\mathrm{T}_{\mathrm{H}} 1$ and $\mathrm{T}_{\mathrm{H}} 2$. $\mathrm{T}_{\mathrm{H}} 1$ cells primarily secrete IFN- - , IL- 2 , and TNF- $\alpha$, while $\mathrm{T}_{\mathrm{H}} 2$ cells primarily secrete IL-4, $5,6,9,10$, and 13, many of which are proinflammatory or profibrotic. $^{23}$ Additionally, epidermal $\gamma \delta \mathrm{T}$ cells respond within hours to tissue damage, releasing numerous growth factors to promote keratinocyte proliferation, immune cell infiltration, and expedite wound closure in mice. ${ }^{101}$ The effect of $\gamma \delta \mathrm{T}$ cells on scar formation remains unknown, though data summarized in previous paragraphs correlating early macrophage infiltration with increased scar size suggest that $\gamma \delta \mathrm{T}$ cells may increase scarring. ${ }^{101}$ Together, these data suggest $T$ cells play an important role in wound repair and scar formation and support the need for controlling the immune system.

Role of other immune cell subtypes in skin scarring. Research into the role of eosinophils, dendritic cells, and B cells on cutaneous scar formation is also lacking. Eosinophils stimulate fibroblasts to upregulate $\alpha$-smooth muscle actin and collagen secretion in bleomycin-induced models of fibrosis and secrete growth factors that promote keratinocyte migration in vitro, suggesting a possible, but unknown, role in dermal scar formation. ${ }^{78}$ Dendritic cells are known to play a role in the rate of reepithelialization, but they likely do not play an important role in scarring. ${ }^{78}$ Finally, one study showed that mice deficient in CD19, a critical positive regulator of $\mathrm{B}$ cells, showed reduced recruitment of neutrophils and macrophages to the wound site, reduced proinflammatory and profibrotic cytokines (including TGF- $\beta$ ), reduced granulation tissue formation, and slower reepithelialization. ${ }^{102}$ This suggests that depleting B cells may be an interesting therapeutic avenue for scar prevention, though there is minimal supporting research.

\section{FUTURE DIRECTIONS}

\section{Therapeutic strategies targeting the immune system for chronic wounds}

Since chronic wounds are often the result of excessive inflammation, controlling the immune response is an attractive avenue for designing novel regenerative strategies. To this end, numerous material-based and molecular strategies have been explored, including targeting the immune response using cytokines, protease inhibitors, miRNA, small 


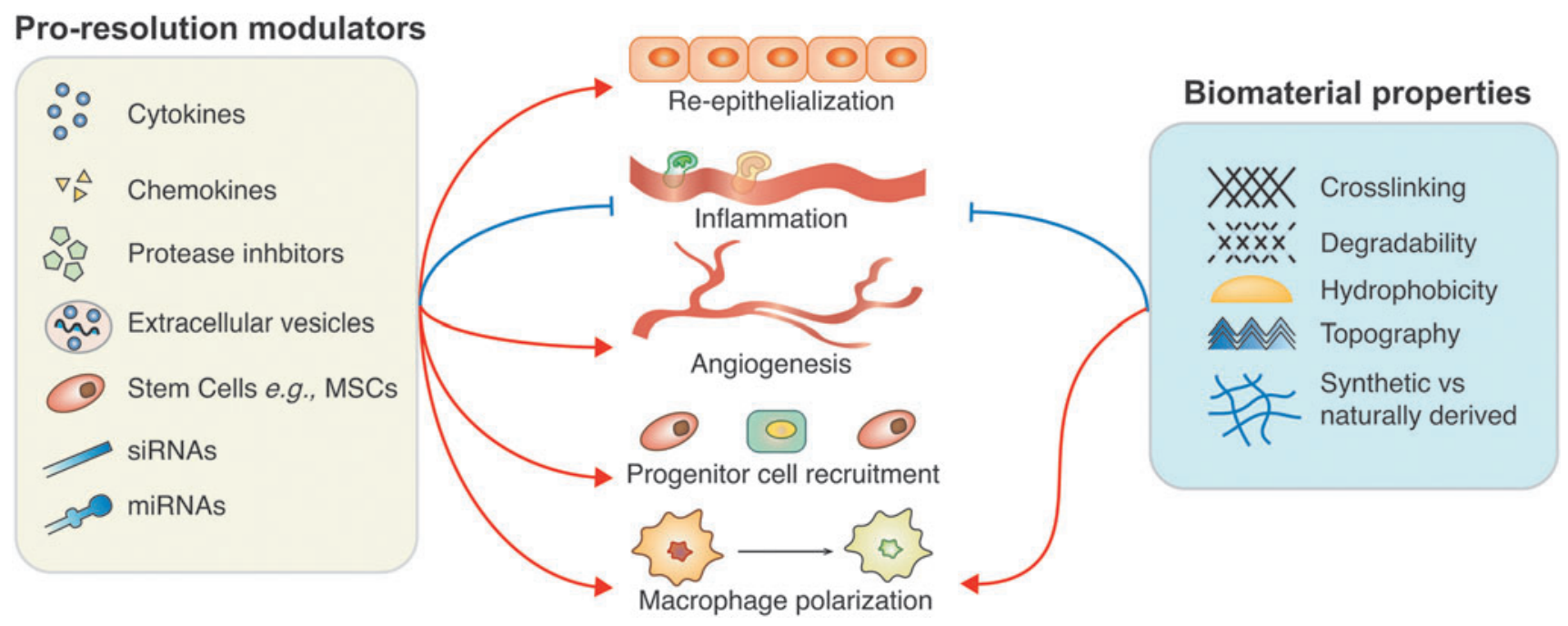

Figure 5. Biomaterial and molecular-based strategies to resolve chronic wounds principally focus on promoting reepithelialization, angiogenesis, progenitor cell recruitment, directing macrophage polarization, and inhibiting the migration of excess inflammatory cells. Current strategies are very diverse, either directly delivering cytokines and growth factors to the wound, or by using siRNAs, miRNAs, stem cells, and EVs to alter cytokine expression and production by cells in the wound bed. Material-based strategies are also being explored, particularly for their potential to direct macrophage polarization. Blue arrows indicate inhibition and red arrows indicate induction. EV, extracellular vesicle; MSC, mesenchymal stem cell; siRNA, small interfering RNA.

interfering RNA (siRNA) and extracellular vesicles (EVs) (Fig. 5).

Biomaterial-based strategies to resolve chronic wounds. Various biomaterials have shown interesting results for promoting wound resolution by modulating the immune system. Current biomaterial-based strategies focus either on macrophage adhesion and recruitment, or on directing their polarization to encourage inflammation resolution. One method of controlling macrophage polarization is to modify the surface chemistry of the biomaterial. Indeed, macrophage adhesion is enhanced on hydrophobic and ionic surfaces. However, even though fewer macrophages and foreign body giant cells (FBGCs) adhere to hydrophillic/ neutral surfaces, those that do adhere secrete more cytokines than macrophages/FBGCs adhered to hydrophobic and ionic surfaces. ${ }^{103}$ This may result from the unique activation of biomaterialadherent macrophages and a phenotypic switch that occurs over time. ${ }^{82}$ Furthermore, it has been demonstrated that monocyte-derived macrophages change their surface protein expression depending upon the chemical composition of the biomaterial surface they are in contact with. ${ }^{104}$ These findings highlight the role of biomaterial surface chemistry in altering macrophage response and activation.

Another important factor to biomaterial design is the surface topography. Indeed, various studies have shown the importance of surface topography in altering macrophage response. ${ }^{105-110}$ For example, surface topography has been altered to mimic the natural ECM structure by imprinting small patterns on the surface, which improves cell adhesion, proliferation, and migration. ${ }^{111}$ These patterns not only affect the function of epithelial cells, endothelial cells, and fibroblasts, but they also promote anti-inflammatory macrophage polarization by encouraging a specific cell shape. ${ }^{111}$ While the effect of incorporating complex matrix topography onto micro-patterned gels has shown enhanced skin regeneration and graft performance in animal models of chronic wounds, its effect on immune cells in this context remains elusive. ${ }^{112}$

The biomaterial origin also affects its immunomodulatory properties. Synthetic biomaterials can be advantageous because they usually avoid an undesirable host immune response driven by the antigens in naturally derived materials. ${ }^{17}$ For example, treatment of wounds in diabetic mice with poly(methacrylic acid-co-methyl methacrylate) (PMMA) beads accelerated chronic wound healing, presumably by increasing sonic hedgehog signaling $(S h h) .{ }^{113} S h h$ is implicated in CD4 $\mathrm{T}$ cell activation and increased proliferation of hematopoietic stem cells (HSCs) and keratinocytes. ${ }^{114,115}$ On the other hand, naturally derived biomaterials can more effectively replace the lost components of the original ECM. Naturally 
derived biomaterials that are commonly used for chronic wound resolution include hyaluronic acid (HA), chitosan, fibrin, and collagen. ${ }^{113}$ For example, using chitosan-based biomaterial $\mathrm{N}$ carboxymethyl chitosan, 5-methyl pyrrolidinone chitosan (MPC) to deliver neurotensin to diabetic wounds in mice induced rapid healing ( $50 \%$ wound area reduction) by reducing levels of TNF- $\alpha$, inflammatory cells, and MMP-9 at the site of injury. ${ }^{116}$ Several other studies have shown similar results using chitosan-based biomaterials for chronic wound repair. ${ }^{117-119}$ Additionally, a clinical trial delivering PRP in a HA scaffold accelerated wound closure by $48 \%$ in 3 days, and lead to complete closure after two doses. ${ }^{5}$ PRP is a known source of numerous proresolution growth factors and cytokines, including PGDF, TGF- $\beta 1$, TGF- $\alpha$, granulocyte macrophage colony-stimulating factor (GM-CSF, also known as colony-stimulating factor 2), and others. ${ }^{120}$

Among naturally derived biomaterials, decellularized ECM possesses immunomodulatory properties. Decellularized ECM is isolated from donor tissues by removing the cellular components using mechanical, chemical, or enzymatic methods. ${ }^{121} \mathrm{~A}$ common origin for ECM-based biomaterials is porcine small intestinal submucosa, which has been shown to modulate the wound healing microenvironment in rats via macrophage polarization. ${ }^{122}$ Interestingly, one mechanism by which decellularized ECM modulates macrophage polarization is through matrix-bound nanovesicles (MBVs), which survive the chemical and enzymatic processes of decellularization. These MBVs contain miRNA that polarizes macrophages to an anti-inflammatory phenotype. ${ }^{123}$ Decellularized and dehydrated human amniotic membrane (DDHAM) products have also demonstrated potential for resolving chronic wounds and are clinically available. Indeed, numerous clinical trials have shown that DDHAM products successfully promote the resolution of chronic wounds that are unresponsive to traditional therapies. ${ }^{124-127}$ Moreover, in a clinical trial evaluating DDHAM allograft safety, patients with various types of chronic wounds did not experience any product-related adverse effects. ${ }^{124}$ DDHAM promotes wound resolution by stimulating the secretion of important growth factors, cytokines and proteases, including PDGFs, TGF- $\alpha$, TGF- $\beta 1$, FGF2 , epidermal growth factor, placental growth factor, granulocyte colony-stimulating factor (also known as colony-stimulating factor 3), IL-4, IL-10, and various TIMPs. ${ }^{128}$ DDHAM also increases the release of stromal cell-derived factor (SDF)-1, which is reduced in diabetic wounds and aids in the recruit- ment of progenitor cells to the site of injury. ${ }^{129,130}$ Therefore, DDHAM appears to be an effective option for designing regenerative strategies for chronic wounds.

Cytokine-based strategies to resolve chronic wounds. Cytokines are obviously critical during the time course of wound healing, making them an attractive target for therapeutic development. For example, IL- $1 \beta$ is part of a proinflammatory positive feedback loop that sustains a persistent proinflammatory wound macrophage phenotype, contributing to impaired healing of diabetic wounds. ${ }^{62,131}$ A study by Mirza et al. showed a significant increase in wound closure in diabetic mice using an antibody to inhibit IL-1 $\beta$. This downregulated proinflammatory macrophages and upregulated prohealing factors in the wound. ${ }^{131}$ Using IL-1 receptor antagonist (IL-1Ra) is another means of blocking IL-1 signaling pathways. Indeed, interaction between IL-1 $\beta$ and IL-1Ra with IL-1R is critical for epithelial wound healing, and the IL-1Ra: IL-1 ratio is known to be higher in fluids from healing wounds than those from chronic wounds (480:1 vs. $7: 1){ }^{62,132}$ Not surprisingly, blocking IL-1 using IL-1Ra has been shown to accelerate wound healing in diabetic mouse corneas. TNF- $\alpha$ is a second proinflammatory cytokine that contributes to a chronic wound state. Neutralizing TNF- $\alpha$ at the incision site significantly accelerated chronic wound healing in mice by decreasing inflammatory cell infiltrates and suppressing proinflammatory macrophage activation. ${ }^{133}$

SDF-1 is another promising chemokine to promote wound healing. For example, delivering nanosized SDF-1 liposomes to diabetic mouse wounds promotes dermal cell proliferation, increases granulation tissue formation, and accelerates wound closure. ${ }^{134}$ Moreover, the liposomes protect SDF-1 from degradation by proteases and serine exopeptidase. However, heparin sulfate present in the wound bed causes dimerization of the SDF-1 liposomes, thereby reducing their bioavailability. A more effective delivery method could probably increase the effectiveness of SDF-1 treatments.

GM-CSF, which facilitates differentiation of HSCs to granulocytes and macrophages, also plays a key role in wound healing. GM-CSF has been shown to accelerate wound closure in diabetic mice by increasing reepithelialization, recruiting leukocytes, increasing angiogenesis, and upregulating proinflammatory mediators, such as IL-6 and macrophage chemoattractant protein (MCP)$1{ }^{135}$ Considering proinflammatory mediators are 
known to exacerbate chronic wounds when present for long periods of time, this study is somewhat paradoxical. However, numerous other studies support GM-CSF effectiveness in resolving chronic wounds. ${ }^{136-137}$ Clinical translation has still not been achieved, though, because most of these studies used intradermal or subcutaneous injections to deliver GM-CSF to the wound site, which raised concerns over injection pain, toxicity, side effects, and uneven distribution. ${ }^{140}$ As an alternative, GM-CSF has been delivered using alginate. In clinical trials, this delivery method accelerated wound healing and relieved pain. ${ }^{140}$ Altogether GM-CSF is a potent cytokine for chronic wounds, but more efficient delivery methods are still required for clinical translation.

Delivery of other cytokines has also shown promise in resolving chronic wounds. Surprisingly, IL-22, a proinflammatory cytokine, helps resolve chronic diabetic wounds in mice by inducing keratinocyte proliferation and signal transducer and activator of transcription 3 (STAT3) activation. ${ }^{141}$ Additionally, anti-inflammatory cytokines have been widely used for macrophage polarization. For example, recombinant IL-10 has been incorporated into dextrin nanogel matrix to resolve chronic wounds, though clinical trial results were not promising. ${ }^{142,144}$ Treatment of skin wounds in diabetic mice using TGF- $\beta 1$ also rescued wound healing and normalized macrophage polarization. ${ }^{72}$ Though not itself a cytokine, using MALP-2 in diabetic mice promoted wound healing by increasing macrophage infiltration and directing antiinflammatory polarization. ${ }^{144}$ MALP-2 stimulates in vivo synthesis of macrophage inflammatory protein (MIP)- $1 \alpha$, MIP-2, and MCP-1. ${ }^{145}$ Phase I clinical trial results using MALP-2 to treat diabetic wounds in 12 patients were also promising. ${ }^{6}$

Since prolonged presence of proinflammatory cytokines may prevent resolution, and both proand anti-inflammatory cytokines are necessary for acute wound healing, sequential delivery of proand anti-inflammatory cytokines could be an interesting strategy for improving chronic wound healing. This concept has been explored in other tissues with some success. For example, to improve bone repair, decellularized bone was engineered to sequentially release IFN- $\gamma$ and IL-4 and implanted in mice at the site of injury. The sequential release promoted macrophage polarization to switch from a pro- to an anti-inflammatory phenotype, resulting in improved wound healing. ${ }^{146}$ Similar strategies for releasing cytokines in a biphasic manner have been reviewed by Alvarez et al. ${ }^{147}$ Considering crosstalk between IFN- $\gamma$ and TGF- $\beta$ is essential for resolving inflammation during skin wound healing, a similar strategy may be useful for chronic wounds. ${ }^{148}$ However, no cytokine-based, chronic wound therapies have reached clinical trials; we need a more effective delivery method to facilitate clinical translation.

Protease inhibitor-based strategies to resolve chronic wounds. The microenvironment of chronic wounds not only has reduced growth factor levels, but also has an imbalance of MMPs and TIMPs. This can lead to the degradation of exogenously delivered growth factors, exacerbating the problem. ${ }^{149}$ Thus, one way to overcome this issue is to deliver protease inhibitors. For example, delivering ND-336, which selectively inhibits MMP-2, MMP-9, and MMP-14, accelerates wound closure in diabetic mice by decreasing inflammation, enhancing reepithelialization, and increasing angiogenesis (Table 2). ${ }^{150}$ Incorporating protease inhibitors into wound dressings has also been explored. For example, combining collagen and oxidized regenerated cellulose matrix into wound dressings improves wound repair by binding to and inactivating MMPs. ${ }^{151}$ Silver dressings and hydrogels, which are antimicrobial have also shown promising results in porcine models and clinical trials. ${ }^{152,153}$ In addition, silver inactivates proteases by displacing zinc from MMPs, which promotes faster granulation tissue formation. ${ }^{152}$ Finally, incorporating oleic acid/albumin formulations into topically applied cotton fiber dressings targets neutrophil elastase in vitro, suggesting that it may help resolve chronic wounds. ${ }^{154}$

miRNA- and siRNA-based strategies to resolve chronic wounds. miRNAs are short, noncoding RNA molecules that repress gene expression by binding to mRNA targets, either causing degradation or inhibiting translation. Interestingly, miRNAs can modulate multiple genes, and studies in diabetic mouse models have shown that they play a key role in orchestrating the inflammatory response during wound healing. An imbalance of these signals may result in an improper inflammatory cascade, leading to the development of chronic wounds. ${ }^{155}$ Indeed, many have been implicated in the regulation of chronic wounds, including miR-21, -99, and $-132 .{ }^{156-158}$ For example, miR-21 promotes fibroblast recruitment by modulating the TGF- $\beta$ pathway, which is significantly reduced in diabetic wounds. ${ }^{156}$ miR-99 overexpression in diabetic wounds increases the migration and proliferation of keratinocytes by regulating the PI3K/Akt pathway, which is implicated in proinflammatory cyto- 
Table 2. List of potential immunomodulatory therapeutics for chronic wounds

\begin{tabular}{|c|c|c|c|c|}
\hline Pharmaceutical & Effects & Outcome & Species & References \\
\hline PMMA & $\begin{array}{l}\text { Activates T cells } \\
\text { Increases HSC and keratinocyte proliferation }\end{array}$ & Increases wound closure & Diabetic mouse & 113 \\
\hline IL-1Ra & Downregulates inflammation triggered by IL-1R & Increases wound closure & Diabetic mouse & $62,131,132$ \\
\hline SDF-1 & Increases dermal cell proliferation promotes granulation tissue formation & Increases wound closure & Diabetic mouse & 134 \\
\hline GM-CSF & $\begin{array}{l}\text { Increases re-epithelialization and angiogenesis } \\
\text { Promotes leukocyte recruitment } \\
\text { Increases collagen deposition } \\
\text { Increases proinflammatory cytokine production }\end{array}$ & Increases wound closure & Diabetic mouse & $135-140$ \\
\hline IL-22 & Increases keratinocyte proliferation & Accelerates wound healing & Diabetic mouse & $141-143$ \\
\hline TGF- $\beta 1$ & $\begin{array}{l}\text { Promotes ECM deposition } \\
\text { Promotes granulation tissue formation directs macrophage polarization }\end{array}$ & Improves diabetic wound healing & Diabetic mouse & 72 \\
\hline MALP-2 & Macrophage infiltration and activation & Promotes early wound closure & $\begin{array}{l}\text { Diabetic mouse } \\
\text { Phase I }\end{array}$ & $6,144,145$ \\
\hline ND-336 & $\begin{array}{l}\text { Inhibits MMPs } \\
\text { Increases reepithelialization and angiogenesis Reduces inflammation }\end{array}$ & Accelerates wound closure & Diabetic mouse & 150 \\
\hline miR-21 & Modulates TGF- $\beta$ pathway & Accelerates wound closure & Diabetic mouse & 156 \\
\hline miR-99 & Regulates PI3K/AKT pathway & Accelerates wound closure & Diabetic mouse & 157 \\
\hline miR-132 & Decreases chemokine secretion reduces leukocyte recruitment & $\begin{array}{l}\text { Promotes transition into } \\
\text { proliferative phase }\end{array}$ & Diabetic mouse & 158 \\
\hline miR-126-3p & Promotes reepithelialization and angiogenesis & Accelerates wound closure & Diabetic mouse & 162 \\
\hline siRNA & Regulates immune cell infiltration decreases protease activity & Accelerates wound closure & Diabetic mouse & $163-165$ \\
\hline $\begin{array}{l}\text { Fibrocyte-derived } \\
\text { exosomes }\end{array}$ & Increases keratinocyte proliferation activates fibroblasts & Accelerates wound closure & Diabetic mouse & 167 \\
\hline PRP gels & Source of cytokines and growth factors & Improves healing in diabetic patients & Phase I & 5,120 \\
\hline DDHAM & $\begin{array}{l}\text { Increase cytokine/growth factor production } \\
\text { Increases progenitor cell recruitment }\end{array}$ & Improves healing in diabetic patients & Phase I & $124-130$ \\
\hline Silver dressings & $\begin{array}{l}\text { Antimicrobial } \\
\text { Inhibits MMPs } \\
\text { Promotes granulation tissue formation }\end{array}$ & Accelerates wound closure & Clinically available & 152,153 \\
\hline
\end{tabular}

DDHAM, dehydrated human amniotic membrane; ECM, extracellular matrix; GM-CSF, granulocyte macrophage colony-stimulating factor; HSC, hematopoietic stem cell; IL, interleukin; IL-1Ra, IL-1 receptor antagonist; MALP, macrophage-activating lipopeptide; PMMA, poly(methacrylic acid-co-methyl methacrylate); PRP, platelet-rich plasma; SDF, stromal cell-derived factor; siRNA, small interfering RNA; TGF, transforming growth factor.

kine secretion and the inhibition of Tregs. ${ }^{157,159,160}$ Finally, miR-132 promotes the transition from the inflammatory phase to the proliferation phase of wound healing by decreasing chemokine secretion and suppressing the NF- $\kappa \mathrm{B}$ pathway, thereby reducing leukocytes recruitment. ${ }^{158}$ Altering miRNA levels at the site of injury is therefore a promising strategy for designing chronic wound therapies (Table 2).

Unfortunately, despite the pivotal role of miRNA in regulating chronic wounds, this path has not been extensively explored and miRNA-based therapeutic strategies are scarce due to the lack of optimal delivery systems. Current delivery systems are based on soluble injections and oligonucleotide conjugation, both of which are inefficient due to bio-fluid degradation. To overcome this issue, Li et al. developed a peptide-based, selfassembled, three-dimensional (3D), supramolecular hydrogel that facilitated miRNA delivery to encapsulated cells, even in the presence of fetal bovine serum. ${ }^{161}$ In another study, miR-126-3p was overexpressed in synovium mesenchymal stem cells (MSCs), which promoted angiogenesis and reepithelization of full-thickness skin defects in a diabetic rat model. ${ }^{162}$ However, these miRNA delivery methods have yet to be translated into the clinic and more efficient delivery strategies are still needed.

siRNA has been widely used for gene silencing purposes to improve wound healing (Table 2). For instance, siRNA against the kelch-like ECH associated protein 1 improved wound closure in a diabetic mouse model by repressing NF-E2-related factor 2. This siRNA was delivered in a lipoproteoplex nanoparticle based system and helped maintain normal levels of inflammatory cells and ROS. ${ }^{163}$ MMP-9 siRNA delivered by $\beta$-CD(D3)7, a cationic, star-shaped polymer, to diabetic rat wounds also accelerated wound closure rate by decreasing MMP-9 expression. ${ }^{164}$ Though not yet tested in the context of chronic wounds, delivering MMP-9 siRNA using liposomes may be more effective as they have higher rates of interference. ${ }^{165}$ Overall, miRNAs and siRNAs have shown promising potential to modulate the immune system and accelerate wound healing, though none have reached clinical trials. Improvements in delivery 
methods are still required for their use as therapeutics in the clinic.

EV-based strategies to resolve chronic wounds. EVs are spherical particles enclosed by a phospholipid bilayer that range from 30 to $2,000 \mathrm{~nm}$ in diameter. They are very important in cell-cell communication, facilitating the exchange of biomolecules such as cytokines, DNA, non-coding RNAs, MMPs, miRNAs, and mRNAs. These biomolecules modify recipient cell protein production, gene expression, and behavior in response to local environmental factors. ${ }^{166} \mathrm{EVs}$ are released by every cell type in the ECM and are rapidly taken up by the targeted cells. Thus, because of these properties, EVs can potentially be used as immunomodulatory molecules to promote wound healing. For example, delivering human fibrocyte-derived exosomes has been shown to accelerate wound closure in diabetic mice by promoting angiogenesis, increasing keratinocyte migration and proliferation, and activating fibroblasts. This was a result of increased expression of heat shock protein- $90 \alpha$, STAT3, and certain miRNAs, including miR-124 (anti-inflammatory), miR-126 (proangiogenic), and miR-21 (regulates collagen deposition). ${ }^{167}$ EVs can also promote wound healing by directing macrophage polarization. For example, exosomes from supernatant of lipopolysaccharide-preconditioned mesenchymal stromal cells promote wound closure by regulating the TLR4/NF- $\kappa \mathrm{B} / \mathrm{STAT} 3 / \mathrm{AKT}$ signaling pathway in diabetic rats. ${ }^{168}$ These studies demonstrate the therapeutic potential of EVs for promoting wound resolution by modulating the immune system. However, like other therapeutic strategies, EV-based therapies have yet to enter clinical trials and more research is required to improve delivery methods.

\section{Therapeutic strategies targeting the immune system for skin scar prevention}

Since the immune system has been shown to play such a critical role in modulating scar formation, recent research has explored both pharmaceuticals and the development of biomaterials that target immune cells to promote scarless wound healing. Leukocytes, namely neutrophils, macrophages, mast cells, and Tregs, are the most common targets for many of these therapeutics (Fig. 6).

Material-based strategies to reduce scarring. Clinically, even when administering a pharmaceutical to promote wound healing, large dermal wounds require bandaging to protect exposed tissue and prevent excessive fluid loss.
Hence, immunomodulatory biomaterials that facilitate scarless healing are very desirable. Many recent studies have focused specifically on immunomodulatory biomaterials that reduce scar formation by delivering MSCs or adipose-derived stem cells (ASCs) to the wound area (Table 3). MSCs have been successfully encapsulated in and delivered to wounds in animal models by gelatin microspheres and microcryogels, or loaded into a $3 \mathrm{D}$ graphene foam. ${ }^{169}$ It has been shown that they release prostaglandin E2 (PGE2), which suppresses the release of proinflammatory cytokines (TNF- $\alpha$, IFN- $\gamma$, IL-6, IL-8, and IL-12p70) and increases the release of anti-inflammatory cytokines (IL-10 and IL-12p40) and TGF- $\beta 1$ by macrophages. ${ }^{170,171}$ Additionally, PGE2 attenuates the proliferation of $\mathrm{T}$ cells in the wound and is a cofactor in the transition from $\mathrm{T}_{\mathrm{H}} 1$ to $\mathrm{T}_{\mathrm{H}} 2$ cells, which favor inflammation resolution and, most likely, tissue regeneration. ${ }^{170}$ The altered cytokine release profile inhibits further neutrophil invasion and respiratory burst, which causes local tissue damage and likely increases scar size. ${ }^{171}$ Delivering ASCs in polyhydroxybutyrate-cohydroxyvalerate constructs achieves a similar outcome in rats and may be more clinically appropriate since the yield following isolation is much higher than MSCs. ${ }^{169,172}$

Aside from the delivery of stem cells, a few other immunomodulatory biomaterial strategies have been explored, some of which are also being explored to promote chronic wound resolution (Table 3). Treatment of dermal wounds in children with neonatal foreskin tissue cultures leads to wound closure and tissue regeneration with minimal scarring. ${ }^{173}$ Since scarless fetal wound healing is dependent upon the reduced inflammatory response, it is likely that treatment of skin wounds with fetal tissue cultures also reduces scarring in adult wounds by attenuating the inflammatory and immune response. ${ }^{169}$ Alternatively, delivering ECM proteins that are more abundant in fetal wounds has shown potential for decreasing scar formation. For example, HA hydrogels minimize scarring by reducing TGF- $\beta 1$ secretion in rabbit and rat models. ${ }^{169}$ Furthermore, incorporating hyaluronan and type III collagen into collagenheparin scaffolds in an attempt to recapitulate the fetal ECM may also aid in scar prevention. ${ }^{113}$

The chemo-physical properties are also an important parameter. Though not studied in relation to dermal scar formation, softer gels and materials with $1-5 \mu \mathrm{m}$ wide gratings reduce the inflammatory response and encourage anti-inflammatory macrophage polarization. ${ }^{174}$ In addition to increasing 


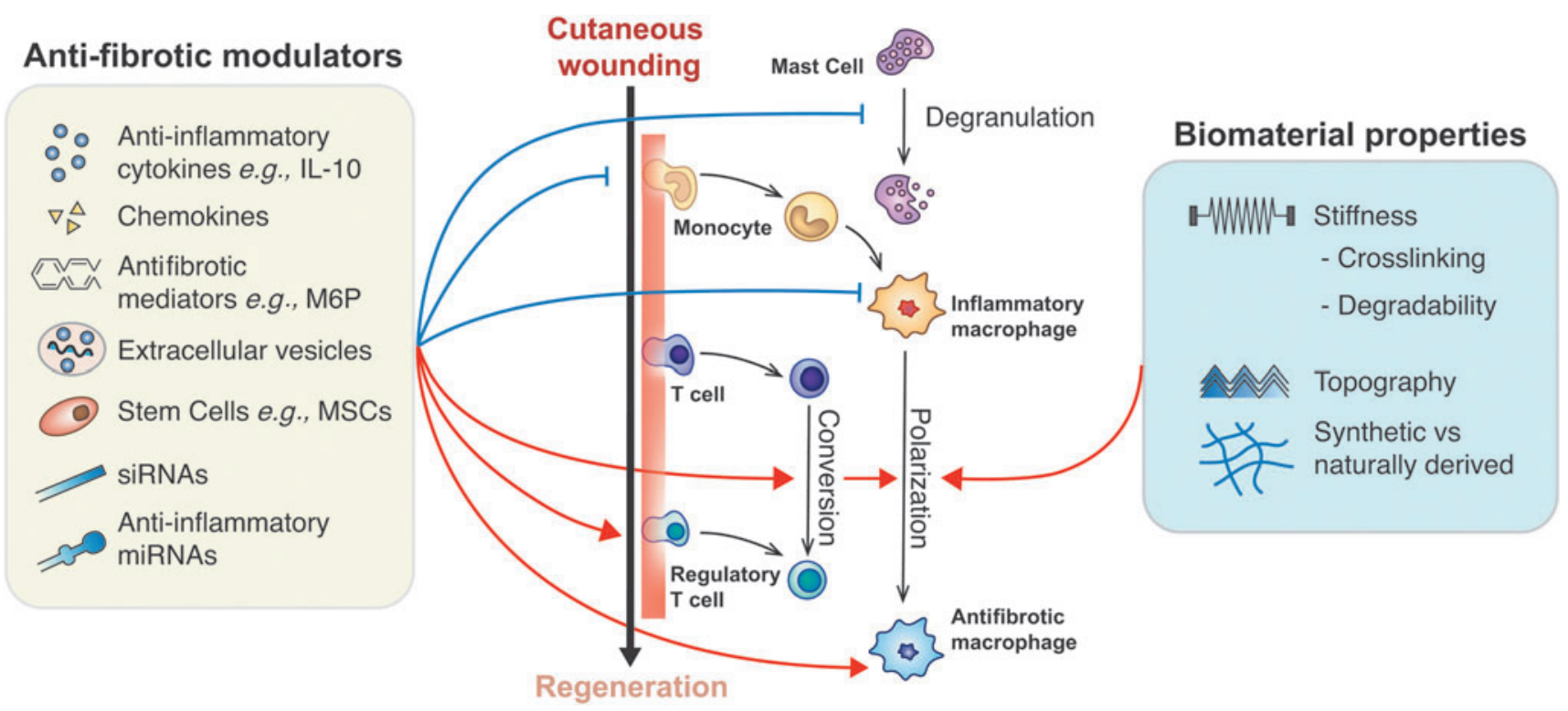

Figure 6. Therapeutic strategies for cutaneous wound regeneration that are targeting the immune system. Therapeutics for scar prevention should, in general, promote antifibrotic macrophage polarization, and prevent mast cell degranulation and inflammatory macrophage polarization/recruitment. Pending future studies confirming the role of Tregs in skin regeneration, therapeutics should also promote their recruitment. This is currently being done via delivery of cytokines, chemokines, other antifibrotic mediators, and stem cells, though delivering siRNA, miRNA, and EVs may also be promising. Biomaterials present a promising means of delivering antifibrotic modulators, and their properties can also encourage macrophage polarization. Black arrows indicate differentiation, blue arrows indicate inhibition, and red arrows indicate induction. M6P, mannose-6-phosphate.

stiffness, cross-linking changes the ultrastructure, composition and surface topology, and prevents material degradation and release of important bioactive matricryptic peptides from naturally derived materials. ${ }^{155}$ Indeed, when using naturally derived materials, chemical cross-linking triggers a chronic foreign body response. Finally, large amounts of cellular material resulting from incomplete decellularization of naturally derived materials

Table 3. Biomaterial-based immunomodulatory strategies to reduce scarring

\begin{tabular}{|c|c|c|}
\hline Material Property & Function & References \\
\hline Deliver stem cells & $\begin{array}{l}\text { Reduces neutrophil recruitment, } \\
\text { prevents respiratory burst } \\
\text { Encourages antifibrotic } \\
\text { macrophage polarization } \\
\text { Attenuates } T \text { cell proliferation, } \\
\text { encourages } T_{H} 2 \text { transition }\end{array}$ & 169-172 \\
\hline Deliver neonatal cells & Attenuates inflammatory response & 169,173 \\
\hline HA-based & Reduces TGF- $\beta 1$ secretion & 113,169 \\
\hline Stiffness & $\begin{array}{l}\text { Softer gels encourage anti-inflammatory } \\
\text { polarization and reduced inflammation }\end{array}$ & 155 \\
\hline Surface topography & $\begin{array}{l}1-5 \mu \mathrm{m} \text { gratings encourage anti-inflammatory } \\
\text { macrophage polarization and } \\
\text { reduce inflammation }\end{array}$ & 174 \\
\hline Chemical cross-linking & $\begin{array}{l}\text { Triggers chronic foreign body } \\
\text { response (increases scarring) }\end{array}$ & 89 \\
\hline
\end{tabular}

HA, hyaluronic acid. elicit detrimental immune responses to promote scar development. ${ }^{155}$ Further elucidating the mechanisms by which these biomaterials reduce the inflammatory response, and developing novel materials that exploit numerous of these properties could lead to considerable improvements in wound care for scar-free dermal regeneration.

Molecular-based strategies to reduce scarring. Recently, many different molecular-based immunomodulatory strategies for preventing scar formation have been explored with some success (Table 4). For example, Chemerin15 (C15), a resolution mediator, has been shown to reduce both neutrophil and macrophage infiltration in mice by around $70 \%$ and $40 \%$, respectively, and restricted their area of infiltration nearly 10 -fold, reducing scar size. ${ }^{175}$ Mechanistically, C15 competitively inhibits its proinflammatory precursor, full-length chemerin. Both proteins interact with the ChemR23 receptor upregulated on neutrophils, macrophages, and keratinocytes following wounding, which plays a role in cell recruitment and adhesion to activated platelets. ${ }^{175}$ Similarly, injecting alpha-melanocytestimulating hormone ( $\alpha \mathrm{MSH})$, a neuropeptide with strong anti-inflammatory and immunomodulatory activity, into mice $30 \mathrm{~min}$ before wounding resulted in significantly smaller scars and a reduction of 
Table 4. List of potential immunomodulatory therapeutics to reduce skin scarring

\begin{tabular}{|c|c|c|c|c|}
\hline Pharmaceutical & Target & Function & Species & Reference \\
\hline C15 & $\begin{array}{l}\text { Neutrophils } \\
\text { Macrophages }\end{array}$ & Reduces recruitment, restricts area of infiltration & Mouse & 175 \\
\hline$\alpha \mathrm{MSH}$ & $\begin{array}{l}\text { Leukocytes } \\
\text { Lymphocytes } \\
\text { Mast cells }\end{array}$ & $\begin{array}{l}\text { Suppresses TNF- } \alpha \text { and IL- } 6 \text { mRNA expression } \\
\text { Induces IL-10 generation of Tregs }\end{array}$ & Mouse & 176,177 \\
\hline $\mathrm{PLC} \varepsilon$ & Leukocytes & Diminishes IL-6, CXCL-1, CXCL-2, and CCL-20 & Mouse & 178 \\
\hline CXCR4 agonist & $\begin{array}{l}\text { Lymphocytes } \\
\text { Monocytes }\end{array}$ & Reduces recruitment & Mouse & 179 \\
\hline PDRN & $\begin{array}{l}\text { Leukocytes } \\
\text { Mast cells }\end{array}$ & $\begin{array}{l}\text { Reduces recruitment } \\
\text { Inhibits degranulation }\end{array}$ & Rat & 180 \\
\hline Curcumin & Leukocytes & Reduces IL-1 $\beta, \mathrm{IL}-6$, and IL-8 & Rabbit & 169 \\
\hline $\mathrm{FM}$ & Cytokine profile & Reduces TGF- $\beta 1$ expression & Mouse & 182 \\
\hline TGF- $\beta 3$ & $\begin{array}{l}\text { Lymphocytes } \\
\text { Macrophages }\end{array}$ & $\begin{array}{l}\text { Induces Tregs } \\
\text { Affects polarization }\end{array}$ & Phase III clinical trial & 7,8 \\
\hline M6P & Cytokine profile & Inhibits TGF- $\beta 1$ and TGF- $\beta 2$ & Phase II clinical trial & 185 \\
\hline IL-10 & $\begin{array}{l}\text { Lymphocytes } \\
\text { Macrophages }\end{array}$ & $\begin{array}{l}\text { Induces Tregs } \\
\text { Encourages antifibrotic macrophage polarization }\end{array}$ & Phase II clinical trial & 3,185 \\
\hline Nefopam & Macrophages & Reduces migration and adhesion & Phase I clinical trial & 186 \\
\hline
\end{tabular}

$\alpha \mathrm{MSH}$, alpha-melanocyte-stimulating hormone; C15, Chemerin 15; CCL, C-C chemokine ligand; CXCL, C-X-C chemokine ligand; CXCR, C-X-C motif chemokine receptor; FM, fibromodulin; M6P, mannose-6-phosphate; PDRN, polydeoxyribonucleotide; PLC $\varepsilon$, phospholipase $\mathrm{C} \varepsilon$; TNF, tumor necrosis factor; Tregs, regulatory T cells.

leukocytes and mast cells. Though the mechanism by which $\alpha \mathrm{MSH}$ reduced scarring was not specifically studied, previous research has shown $\alpha \mathrm{MSH}$ suppresses IL-1, TNF- $\alpha$, IFN- $\gamma$, and IL-6 mRNA expression, and induces Tregs via IL-10. ${ }^{176,177}$ Mast cells can be specifically targeted to reduce scar formation by administering stabilizers to prevent degranulation, such as cromoglicic acid and ketotifen, using tyrosine kinase inhibitors to reduce mast cell numbers following injury, or by neutralizing chymase activity. ${ }^{92}$ Another potential therapeutic target for reducing leukocyte recruitment is Phospholipase $\mathrm{C} \varepsilon$ (PLC $\varepsilon$ ). PLC $\varepsilon$ knockout mice have significantly reduced levels of proinflammatory cytokines and chemokines, including IL-6, CXCL-1, CXCL-2, and C-C chemokine ligand (CCL)-20, and heal dermal wounds with less scarring. ${ }^{178}$ SDF-1, which is potently chemotactic for lymphocytes and monocytes, binds to the CXCR4 and CXCR7 receptors. Targeting that pathway using CXCR4 agonist CTCE-9908 decreased cell recruitment and reduced scarring in mice. ${ }^{179}$ Similarly, administration of polydeoxyribonucleotide (PDRN) to excisional skin wounds in rats significantly reduced scarring. PDRN inhibits mast cell degranulation, decreases inflammatory cell recruitment, and reduces the amount of proinflammatory mediators (including TNF- $\alpha$, IL-6, and HMGB-1) at the wound site. ${ }^{180}$ Interestingly, exploiting oral tolerance to common dietary proteins, specifically zein, which is found in corn, can also result in less prominent scarring in mice. Since reexposure to orally tolerated proteins blocks nonspecific inflammation, mice that received a parenteral injection of zein immediately before wounding showed decreased amounts of proinflammatory cytokines, increased amounts of antiinflammatory cytokines, and had smaller scars 40 days postwounding. ${ }^{181}$ Curcumin is a natural material that also reduces proinflammatory cytokines, including IL-1 $\beta$, IL-6, and IL-8 to reduce scarring in rabbits. ${ }^{169}$ Finally, though its mechanism of action is still somewhat unclear, fibromodulin, a proteoglycan that participates in the assembly of collagen fibers in the ECM, was recently found to restore scar-free wound healing in late-stage gestational murine wounds by decreasing TGF- $\beta 1$ expression. ${ }^{182}$

While the strategies above are still in the phases of initial exploration and preclinical development, four molecular-based strategies for reducing scar formation have reached clinical trials: TGF- $\beta 3$ (planned trade name Avotermin), M6P, IL-10 (planned trade name Prevascar), and nefopam (planned trade mane ScarX). TGF- $\beta 3$ is a cytokine whose presence is associated with scar-free wound healing. While its role on the immune response has yet to be carefully evaluated, there is evidence that it induces Tregs and affects macrophage polarization. ${ }^{90,183,184}$ Renovo Ltd. translated numerous preclinical studies showing a decrease in scarring following local administration of TGF- $\beta 3$ before and after operation into phase I and II clinical trials. ${ }^{8}$ Further evaluation was halted after Avotermin failed to meet its efficacy endpoints during phase III, potentially because the dose was halved. However, since temporal variation critically affects healing, continuing studies are exploring the efficacy of continuously delivering TGF- $\beta 3$ in de- 
creasing scarring. ${ }^{7} \mathrm{M} 6 \mathrm{P}$ is a potent inhibitor of TGF- $\beta 1$ and TGF- $\beta 2$. While it was successful in phase I clinical trials, in the phase II exploratory trial neither topical nor intradermal application showed statistical significance. ${ }^{185}$ A phase II trial injecting human recombinant IL-10 into surgical wound margins showed a statistically significant decrease in scar development. IL-10 not only induces Tregs, but also leads to an anti-inflammatory, alternatively activated macrophage polarization. ${ }^{3}$ In a second phase II trial that extended for longer time points following treatment, there was actually more scarring following IL-10 treatment compared with placebo controls. ${ }^{185}$ Finally, topical nefopam, was first developed as a non-narcotic analgesic drug and attenuates $\beta$-catenin levels, thereby affecting the migration and adhesion of macrophages. Phase I clinical trials for its effectiveness in reducing dermal scarring have just begun, though around 30 years of data exist to demonstrate its systemic safety. ${ }^{186}$

Finally, interesting directions for future development of molecular-based scar prevention strategies may focus on chemokine receptor pathways. There exist considerable data supporting both positive and negative roles of different chemokines and cytokines in wound healing and scar formation, ${ }^{179}$ yet few of these pathways have been explored as therapeutics. Some chemokine receptor pathways that show promise for successful therapeutic developments for skin regeneration include $\mathrm{C}-\mathrm{X} 3-\mathrm{C}$ chemokine motif receptor (CX3CR)1, C-C chemokine receptor (CCR)2 and CXCR3. ${ }^{179,187,188}$

As previously emphasized, a major letdown of many current strategies is their reliance on very high concentration (supra-physiological) doses, which do not remain at the wound site for long enough without performing multiple deliveries. Hence, a critical aspect for these strategies is to develop appropriate delivery systems. For example, various protein engineering strategies have been developed to confer a high affinity of therapeutics to the endogenous ECM. ${ }^{189}$ These approaches allow the retention of the therapeutic at the delivery site without using biomaterials. Perhaps, using a similar delivery strategy would improve the clinical efficacy of protein-based therapeutics for scar prevention. Extensive research has also been done developing controlled release polymers, though many remain untested in the context of wound healing and scar formation. ${ }^{190}$ Ongoing research in this area will likely potentiate therapeutic effectiveness of the molecular-based targets discussed herein.

\section{SUMMARY}

Recent findings have greatly improved our understanding of the roles of the immune system in acute wound healing. The immune response is either dysregulated in chronic wounds, or leads to undesirable scar development. Macrophages clearly play an important role, especially through their phenotypic changes. Further clarifying activation pathways could yield therapies that directly impact their polarization to improve wound outcomes. Additionally, Tregs have been shown to have regenerative properties in other tissues, yet there is a lack of information explaining their role in wound resolution and scar formation. ${ }^{3}$

Ultimately, translating current and future immune-modulatory therapeutics hinges on the development of improved drug delivery methods. Many therapies that have reached clinical trials failed because current delivery methods rely on supra-physiological bolus doses rather than controlled, sustained release. Because of natural drug clearance, meeting both safety and efficacy benchmarks in this way is incredibly challenging. This is especially evident in chronic wound therapies, which have fallen short largely because of inefficient delivery methods. Hence, novel delivery systems are critical for successful translation of therapeutics currently being explored and those to be explored in the future. Perhaps certain strategies that failed clinical trials in the past may become successful using novel delivery strategies.

\section{ACKNOWLEDGMENTS AND FUNDING SOURCES}

This work was supported in part by the research grant of Astellas Foundation for Research on Metabolic Disorders and by the Australian Research Council (DE170100398) to M.M.M. and a Whitaker International Fellowship awarded to J.L.

\section{AUTHOR DISCLOSURE AND GHOSTWRITING}

No competing financial interests exist. The authors listed expressly wrote the content of this article. No ghostwriters were used to write this article.

\section{ABOUT THE AUTHORS}

Jacqueline Larouche, BS, received her degree in Biomedical Engineering from the Georgia Institute of Technology. She is currently a Whitaker Fellow at the Australian Regenerative Medicine Institute (ARMI) in Monash University, where she focuses on growth factor engineering to enhance regeneration. Sumit Sheoran, MSc, re- 
ceived his degree from the Manipal University School of Regenerative Medicine and is currently a research fellow at ARMI. Kenta Maruyama, MD, PhD, obtained his degrees from Keio University and Osaka University School of Medicine. After clinical residency at the National Hospital Organization Tokyo Medical Center, he joined the Immunology Frontier Research Center at Osaka University as a research fellow and became Assistant Professor in 2014. His research focuses on bone-biology, pain-biology, molecular-immuno-physiology, and geriatric medicine. Mikaël M. Martino, PhD, obtained his degree in Biotechnology and Bioengineering at the Ecole Polytechnique Fédérale de Lausanne. Then, he became a postdoctoral fellow and an Assistant Professor in the Immunology Frontier Research Centre at Osaka University, focusing on how the immune system influences tissue regeneration. In 2016, he became a European Molecular Biology Laboratory (EMBL) Australia group leader at ARMI. His long-term goal is to work at the interface between bioengineering and immunology for designing efficient regenerative medicine strategies.

\section{TAKE-HOME MESSAGES}

- Immune cells and immune mediators are intimately involved in every stage of wound healing. Early studies showed improved healing in immunodeficient mice and fetuses, sparking increased research into the differential role of immune cells in wound repair.

- Chronic wounds are trapped in a chronic inflammatory state, precluding restoration of the normal anatomical structure and function in sequential manner

- In chronic wounds, increased biofilm load leads to imbalance between inflammatory and anti-inflammatory mediators. This creates a steady state of hyper-inflammation and the immune system is unable to overwhelm the bacterial load.

- Hyper-inflammation causes overproduction of MMPs and ROS and decreases in TIMPs, contributing to development of chronic wounds.

- Macrophage phenotype conversion from proinflammatory to antiinflammatory macrophage is critical in the process of normal wound healing. This conversion is impaired in chronic wounds.

- Macrophages, mast cells, neutrophils, and most T cells promote rapid wound closure and scar formation. Inducing Tregs and promoting antifibrotic macrophage polarization may help attenuate the immune response to promote scarless healing.

- Scar therapies mostly focus on reducing immune cell recruitment, inducing Tregs or interfering with the macrophage polarization and TGF- $\beta$ pathways.

- Development of a novel drug delivery system that controls therapeutic release at the wound site is required to safely and effectively resolve chronic wounds and promote scarless healing.

\section{REFERENCES}

1. Sen CK, Gordillo GM, Roy S, et al. Human skin wounds: a major and snowballing threat to public health and the economy. Wound Repair Regen 2010;17:763-771.

2. Weiser TG, Regenbogen SE, Thompson KD, et al. An estimation of the global volume of surgery: a modelling strategy based on available data. Lancet 2008;372:139-144.

3. Julier Z, Park AJ, Briquez PS, Martino MM. Promoting tissue regeneration by modulating the immune system. Acta Biomater 2017;53:13-28.

4. Eming SA, Martin P, Tomic-Canic M. Wound repair and regeneration: mechanisms, signalling, and translation. Wound Healing 2014;6:265sr6.

5. Ramos-Torrecillas J, Garcia-Martinez O, De Luna-Bertos E, Ocana-Peinado FM, Ruiz C. Effectiveness of platelet-rich plasma and hyaluronic acid for the treatment and care of pressure ulcers. Biol Res Nurs 2015;17:152-158.
6. Niebuhr M, Muhlradt PF, Wittmann M, Kapp A, Werfel T. Intracutaneous injection of the macrophage-activating lipopeptide-2 (MALP-2) which accelerates wound healing in mice-a phase I trial in 12 patients. Exp Dermatol 2008; 17:1052-1056

7. Samadikuchaksaraei A, Mehdipour A, Roudkenar $\mathrm{MH}$, et al. A dermal equivalent engineered with TGF- $\beta 3$ expressing bone marrow stromal cells and amniotic membrane: cosmetic healing of full-thickness skin wounds in rats. Artif Organs 2016;40:E266-E279.

8. Ferguson MWJ, Duncan J, Bond J, et al. Prophylactic administration of avotermin for improvement of skin scarring: three double-blind, placebo-controlled, phase 1/II studies. Lancet 2009;373:1264-1274.

9. Delavary BM, van der Veer WM, van Egmond M, Niessen FB, Beelen RHJ. Macrophages in skin injury and repair. Immunobiology 2011;216: 753-762.

10. Diegelmann RF, Evans MC. Wound healing: an overview of acute, fibrotic and delayed healing. Front Biosci 2004;9:283-289

11. Szpaderska AM, Egozi El, Gamelli RL, DiPietro $L A$. The effect of thrombocytopenia on dermal wound healing. J Invest Dermatol 2003;120: 1130-1137.

12. Martin P, Leibovich SJ. Inflammatory cells during wound repair: the good, the bad and the ugly. Trends Cell Biol 2005;15:599-607.

13. Deppermann C, Cherpokova D, Nurden P, et al Gray platelet syndrome and defective thromboinflammation in Nbeal2-deficient mice. J Clin Invest 2013;123:3331-3342.

14. Martinez-Zapata MJ, Marti-Carvajal AJ, Sola I, et al. Autologous platelet-rich plasma for 
treating chronic wounds. Cochrane Database Syst Rev 2012;10:CD006899.

15. Martinez-Zapata MJ, Marti-Carvajal AJ, Sola I, et al. Autologous platelet-rich plasma for treating chronic wounds. Cochrane Database of Systematic Reviews 2016:CD006899.

16. Suthar M, Gupta S, Bukhari S, Ponemone V. Treatment of chronic non-healing ulcers using autologous platelet rich plasma: a case series. J Biomed Sci 2017:24:16.

17. Temenoff JS, Mikos AG. Biomaterials: The Intersection of Biology and Materials Science, 1st ed. Upper Saddle River, NJ: Pearson Prentice Hall, 2008.

18. Kolaczkowska E, Kubes P. Neutrophil recruitment and function in health and inflammation. Nat Rev Immunol 2013;13:159-175.

19. Weiss SJ. Tissue destruction by neutrophils. N Engl J Med 1989;320:365-376.

20. Brinkmann V, Reichard U, Goosmann C, et al. Neutrophil extracellular traps kill bacteria. Science 2004;303:1532-1535.

21. Wilgus TA, Roy S, McDaniel JC. Neutrophils and wound repair: positive actions and negative reactions. Adv Wound Care (New Rochelle) 2013; 2:379-388

22. Devalaraja RM, Nanney LB, Du J, et al. Delayed wound healing in CXCR2 knockout mice. J Invest Dermatol 2000;115:234-244.

23. Zaja-Milatovic S, Richmond A. CXC chemokines and their receptors: a case for a significant biological role in cutaneous wound healing. Histol Histopathol 2008;23:1399-1407.

24. Dovi JV, He LK, DiPietro LA. Accelerated wound closure in neutrophil-depleted mice. J Leukoc Biol 2003;73:448-455.

25. Willenborg S, Eming SA. Macrophages-sensors and effectors coordinating skin damage and repair. J Ger Soc Dermatol 2014;12:214-221.

26. Murray PJ, Wynn TA. Protective and pathogenic functions of macrophage subsets. Nature 2011; 11:723-737.

27. Macdonald KP, Palmer JS, Cronau S, et al. An antibody against the colony-stimulating factor 1 receptor (CSF1R) depletes the resident subset of monocytes and tissue and tumor-associated macrophages but does not inhibit inflammation. Blood 2010;116:3955-3963.

28. Murray PJ, Allen JE, Biswas SK, et al. Macrophage activation and polarization: nomenclature and experimental guidelines. Immunity 2014;41: $14-20$.

29. Leibovich SJ, Ross R. The role of the macrophage in wound repair. A study with hydrocortisone and antimacrophage serum. Am J Pathol 1975;78:71-100.

30. Subramaniam M, Saffaripour S, Van De Water $L$, et al. Role of endothelial selectins in wound repair. Am J Pathol 1997;150:1701-1709.
31. Nagaoka T, Kaburagi $Y$, Hamaguchi $Y$, et al. Delayed wound healing in the absence of intercellular adhesion molecule-1 or L-selectin expression. Am J Pathol 2000;157:237-247.

32. Mori R, Kondo T, Ohshima T, Ishida Y, Mukaida $\mathrm{N}$. Accelerated wound healing in tumor necrosis factor receptor p55-deficient mice with reduced leukocyte infiltration. FASEB J 2002;16: 963-974.

33. DiPietro LA, Polverini PJ. Role of the macrophage in the positive and negative regulation of wound neovascularization. Behring Inst Mitt 1993:238-247.

34. Lucas T, Waisman A, Ranjan R, et al. Differential roles of macrophages in diverse phases of skin repair. J Immunol 2010;184:3964-3977.

35. Jetten N, Verbruggen S, Gijbels MJ, Post MJ, De Winther MP, Donners MM. Anti-inflammatory M2, but not pro-inflammatory M1 macrophages promote angiogenesis in vivo. Angiogenesis 2014; 17:109-118.

36. Sallusto F, Baggiolini M. Chemokines and leukocyte traffic. Nat Immunol 2008;9:949-952.

37. Baggiolini M. Chemokines and leukocyte traffic. Nature 1998;392:565-568.

38. Farrar MA, Schreiber RD. The molecular cell biology of interferon-gamma and its receptor. Annu Rev Immunol 1993;11:571-611.

39. Xu P, Fu X, Xiao N, et al. Involvements of gammadeltaT lymphocytes in acute and chronic skin wound repair. Inflammation 2017;40:14161427.

40. Jameson J, Ugarte $K$, Chen N, et al. A role for skin gammadelta $T$ cells in wound repair. Science 2002;296:747-749.

41. Pang DJ, Neves JF, Sumaria N, Pennington DJ. Understanding the complexity of $\gamma \delta$ T-cell subsets in mouse and human. Immunology 2012; 136:283-290.

42. Toulon A, Breton L, Taylor KR, et al. A role for human skin-resident $T$ cells in wound healing. $J$ Exp Med 2009;206:743-750.

43. Lei H, Schmidt-Bleek K, Dienelt A, Reinke P, Volk $H D$. Regulatory $T$ cell-mediated anti-inflammatory effects promote successful tissue repair in both indirect and direct manners. Front Pharmacol 2015;6:184.

44. Liu G, Ma H, Qiu L, et al. Phenotypic and functional switch of macrophages induced by regulatory CD4+CD25+ T cells in mice. Immunol Cell Biol 2011;89:130-142.

45. Nosbaum A, Prevel N, Truong HA, Mehta P, Ettinger M, Scharschmidt TC, Ali NH, Pauli ML, Abbas AK, Rosenblum MD. Cutting edge: regulatory $T$ cells facilitate cutaneous wound healing. J Immunol 2016;196:2010-2014.

46. Brubaker AL, Schneider DF, Kovacs EJ. Neutrophils and natural killer $T$ cells as negative regulators of wound healing. Expert Rev Dermatol 2011;6:5-8.
47. Schneider DF, Palmer JL, Tulley JM, et al. A novel role for NKT cells in cutaneous wound repair. J Surg Res 2011;168:325-333.e321.

48. Wynn TA. Cellular and molecular mechanisms of fibrosis. J Pathol 2008;214:199-210.

49. Fertin C, Nicolas JF, Gillery P, Kalis B, Banchereau J, Maquart FX. Interleukin-4 stimulates collagen synthesis by normal and scleroderma fibroblasts in dermal equivalents. Cell Mol Biol 1991;37:823-829.

50. Eming SA, Hammerschmidt M, Krieg T, Roers A. Interrelation of immunity and tissue repair or regeneration. Semin Cell Dev Biol 2009;20: 517-527.

51. Stojadinovic A, Carlson JW, Schultz GS, Davis TA, Elster EA. Topical advances in wound care. Gynecol Oncolol 2008;111(2 Suppl):S70-S80.

52. Eming SA, Koch M, Krieger A, et al. Differential proteomic analysis distinguishes tissue repair biomarker signatures in wound exudates obtained from normal healing and chronic wounds. J Proteome Res 2010;9:4758-4766.

53. Schultz GS, Mast BA. Molecular analysis of the environments of healing and chronic wounds: cytokines, proteases and growth factors. Prim Intention 1999;7:7-15.

54. Ben-Porath I, Weinberg RA. The signals and pathways activating cellular senescence. Int J Biochem Cell Biol 2005;37:961-976.

55. Wysocki AB, Staiano-Coico L, Grinnell F. Wound fluid from chronic leg ulcers contains elevated levels of metalloproteinases MMP-2 and MMP9. J Invest Dermatol 1993;101:64-68.

56. Weckroth M, Vaheri A, Lauharanta J, Sorsa T, Konttinen YT. Matrix metalloproteinases, gelatinase and collagenase, in chronic leg ulcers. J Invest Dermatol 1996;106:1119-1124.

57. Saarialho-Kere UK. Patterns of matrix metalloproteinase and TIMP expression in chronic ulcers. Arch Dermatol Res 1998;290 Suppl:S47-S54.

58. Grinnell F, Zhu M. Fibronectin degradation in chronic wounds depends on the relative levels of elastase, alpha1-proteinase inhibitor, and alpha2-macroglobulin. J Invest Dermatol 1996; 106:335-341.

59. Grinnell F, Ho CH, Wysocki A. Degradation of fibronectin and vitronectin in chronic wound fluid: analysis by cell blotting, immunoblotting, and cell adhesion assays. J Invest Dermatol 1992;98:410-416.

60. Rao CN, Ladin DA, Liu YY, Chilukuri K, Hou ZZ, Woodley DT. Alpha 1-antitrypsin is degraded and non-functional in chronic wounds but intact and functional in acute wounds: the inhibitor protects fibronectin from degradation by chronic wound fluid enzymes. J Invest Dermatol 1995; 105:572-578.

61. Herrick S, Ashcroft G, Ireland G, Horan M, McCollum C, Ferguson M. Up-regulation of elastase in acute wounds of healthy aged humans 
and chronic venous leg ulcers are associated with matrix degradation. Lab Invest 1997;77:281-288.

62. Zhao R, Liang $H$, Clarke E, Jackson C, Xue M. Inflammation in chronic wounds. Int $\mathrm{J}$ Mol Sci 2016;17:pii: E2085.

63. Wong SL, Demers M, Martinod K, et al. Diabetes primes neutrophils to undergo NETosis, which impairs wound healing. Nat Med 2015; 21:815-819.

64. Roth Flach RJ, Czech MP. NETs and traps delay wound healing in diabetes. Trends Endocrinol Metab 2015;26:451-452

65. Fadini GP, Menegazzo L, Rigato M, et al. NETosis delays diabetic wound healing in mice and humans. Diabetes 2016;65:1061-1071.

66. Papayannopoulos V. Sweet NETs, bitter wounds. Immunity 2015;43:223-225.

67. Khanna S, Biswas S, Shang Y, et al. Macrophage dysfunction impairs resolution of inflammation in the wounds of diabetic mice. PLoS One 2010; 5:e9539.

68. Hanses F, Park S, Rich J, Lee JC. Reduced neutrophil apoptosis in diabetic mice during staphylococcal infection leads to prolonged Tnfalpha production and reduced neutrophil clearance. PLoS One 2011;6:e23633.

69. Loots MA, Lamme EN, Zeegelaar J, Mekkes JR, Bos JD, Middelkoop E. Differences in cellular infiltrate and extracellular matrix of chronic diabetic and venous ulcers versus acute wounds. $J$ Invest Dermatol 1998;111:850-857.

70. Snyder RJ, Lantis J, Kirsner RS, Shah V, Molyneaux M, Carter MJ. Macrophages: a review of their role in wound healing and their therapeutic use. Wound Repair Regen 2016;24:613-629.

71. Sindrilaru A, Peters T, Wieschalka $S$, et al. An unrestrained proinflammatory M1 macrophage population induced by iron impairs wound healing in humans and mice. J Clin Invest 2011; 121:985-997.

72. Okizaki S, Ito Y, Hosono K, et al. Suppressed recruitment of alternatively activated macrophages reduces TGF-beta1 and impairs wound healing in streptozotocin-induced diabetic mice. Biomed Pharmacother 2015;70:317-325.

73. Hesketh M, Sahin KB, West ZE, Murray RZ. Macrophage phenotypes regulate scar formation and chronic wound healing. Int J Mol Sci 2017; 18:pii: E1545.

74. Subramaniam K, Pech CM, Stacey MC, Wallace HJ. Induction of MMP-1, MMP-3 and TIMP-1 in normal dermal fibroblasts by chronic venous leg ulcer wound fluid. Int Wound J 2008;5:79-86.

75. Eming SA, Krieg T, Davidson JM. Inflammation in wound repair: molecular and cellular mechanisms. J Invest Dermatol 2007;127:514-525.

76. Mendez MV, Stanley A, Park HY, Shon K, Phillips T, Menzoian J0. Fibroblasts cultured from venous ulcers display cellular characteristics of senescence. J Vasc Surg 1998;28:876-883
77. Stojadinovic 0, Yin N, Lehmann J, Pastar I, Kirsner RS, Tomic-Canic M. Increased number of Langerhans cells in the epidermis of diabetic foot ulcers correlates with healing outcome. Immunol Res 2013;57:222-228.

78. Cash J, P. Martin. Myeloid cells in cutaneous wound repair. Microbiol Spectr 2016:4. doi: 10.1128/microbiolspec.MCHD-0017-2015

79. Costerton JW, Stewart PS, Greenberg EP. Bacterial biofilms: a common cause of persistent infections. Science 1999:284:1318-1322.

80. Wolcott RD, Rhoads DD, Dowd SE. Biofilms and chronic wound inflammation. J Wound Care 2008;17:333-341.

81. Roy S, Elgharably $H$, Sinha M, et al. Mixedspecies biofilm compromises wound healing by disrupting epidermal barrier function. J Pathol 2014;233:331-343

82. Wilgus TA. Immune cells in the healing skin wound: influential players at each stage of repair. Pharmacol Res 2008;58:112-116.

83. Tan J, Wu J. Current progress in understanding the molecular pathogenesis of burn scar contracture. Burns Trauma 2017:5:14.

84. Brant JO, Lopez MC, Baker HV, Barbazuk WB Maden M. A comparative analysis of gene expression profiles during skin regeneration in Mus and Acomys. PLoS one 2015;10:e0142931.

85. Zhu Z, Ding J, Ma Z, Iwashina T, Tredget EE. Systemic depletion of macrophages in the subacute phase of wound healing reduces hypertrophic scar formation. Wound Repair Regen 2016;24:644-656.

86. Amini-Nik S, Cambridge E, Yu W, et al. BCatenin-regulated myeloid cell adhesion and migration determine wound healing. J Clin Invest 2014;126:2599-2610.

87. Dardenne $A D$, Wulff $B C$, Wilgus TA. The alarmin HMGB-1 influences healing outcomes in fetal skin wounds. Wound Repair Regen 2013; 21:282-291.

88. Broek LJ, Veer WM, Jong EH, Gibbs S, Niessen F. Suppressed inflammatory gene expression during human hypertrophic scar compared to normotrophic scar formation. Exp Dermatol 2015: 24:623-629

89. Brown BN, Londono R, Tottey S, et al. Macrophage phenotype as a predictor of constructive remodeling following the implantation of biologically derived surgical mesh materials. Acta Biomater 2012;8:978-987.

90. Rodero MP, Khosrotehrani K. Skin wound healing modulation by macrophages. Int J Clin Exp Pathol 2010;3:643-653.

91. Murray LA, Chen Q, Kramer MS, et al. TGF-beta driven lung fibrosis is macrophage dependent and blocked by Serum amyloid P. Int J Biochem Cell Biol 2011:43:154-162.

92. Wilgus TA, Wulff BC. The importance of mas cells in dermal scarring. Adv Wound Care 2014; 3:356-365.
93. Au SR, Au K, Saggers GC, Kame N, Ehrlich HP. Rat mast cells communicate with fibroblasts via gap junction intercellular communications. J Cell Biochem 2007:100:1170-1177.

94. Foley T, Saggers GC, Moyer K, Ehrlich HP. Rat mast cells enhance fibroblast proliferation and fibroblast-populated collagen lattice contraction through gap junctional intercellular communications. Plastic Reconstr Surg 2011;127: 1478-1486.

95. Pistorio A, Ehrlich HP. Modulatory effects of connexin-43 expression on gap junction intercellular communications with mast cells and fibroblasts. J Cell Biochem 2011;112: 1441-1449

96. Foley T, Ehrlich HP. Through gap junction communications, co-cultured mast cells and fibroblasts generate fibroblast activities allied with hypertrophic scarring. Plast Reconstr Surg 2013; 131:1036-1044.

97. Chen L, Schrementi ME, Ranzer MJ, Wilgus TA, DiPietro LA. Blockade of mast cell activation reduces cutaneous scar formation. PLOS One 2014;9:e85226.

98. Wulff BC, Parent AE, Meleski MA, DiPietro LA Schrementi ME, Wilgus TA. Mast cells contribute to scar formation during fetal wound healing. J Invest Dermatol 2012;132:458-465.

99. Willenborg S, Eckes B, Brinckmann J, et al. Genetic ablation of mast cells redefines the role of mast cells in skin wound healing and bleomycin-induced fibrosis. J Invest Dermatol 2014;134:2005-2015.

100. Chen L, Mehta ND, Zhao Y, DiPietro LA. Absence of CD4 or CD8 lymphocytes changes infiltration of inflammatory cells and profiles of cytokine expression in skin wounds, but does not impair healing. Exp Dermatol 2014;23:189-194.

101. Havran WL, Jameson JM. Epidermal T cells and wound healing. J Immunol 2010;184:5423-5428.

102. Iwata $Y$, Yoshizaki A, Komura K, et al. CD19, a response regulator of $B$ lymphocytes, regulates wound healing through hyaluronan-induced TLR4 signaling. Am J Pathol 2009;175:649-660.

103. Jones JA, Chang DT, Meyerson $H$, et al. Proteomic analysis and quantification of cytokines and chemokines from biomaterial surfaceadherent macrophages and foreign body giant cells. J Biomed Mater Res A 2007;83:585-596.

104. Dinnes DL, Marcal H, Mahler SM, Santerre JP, Labow RS. Material surfaces affect the protein expression patterns of human macrophages: a proteomics approach. J Biomed Mater Res A 2007:80:895-908.

105. Yim EK, Leong KW. Significance of synthetic nanostructures in dictating cellular response. Nanomedicine 2005;1:10-21.

106. Fink J, Fuhrmann R, Scharnweber T, Franke RP. Stimulation of monocytes and macrophages: possible influence of surface roughness. Clin Hemorheol Microcirc 2008;39:205-212. 
107. Curtis A, Wilkinson C. Topographical control of cells. Biomaterials 1997;18:1573-1583.

108. Wojciak-Stothard B, Curtis A, Monaghan W, MacDonald K, Wilkinson C. Guidance and activation of murine macrophages by nanometric scale topography. Exp Cell Res 1996;223:426-435.

109. Chen S, Jones JA, Xu Y, Low HY, Anderson JM, Leong KW. Characterization of topographical effects on macrophage behavior in a foreign body response model. Biomaterials 2010;31:3479-3491.

110. Waterfield JD, Ali TA, Nahid F, Kusano K, Brunette DM. The effect of surface topography on early NFkappaB signaling in macrophages. J Biomed Mater Res A 2010;95837-847.

111. McWhorter FY, Wang T, Nguyen P, Chung T, Liu WF. Modulation of macrophage phenotype by cell shape. Proc Natl Acad Sci U S A 2013;110: 17253-17258.

112. Clement AL, Moutinho TJ, Jr, Pins GD. Micropatterned dermal-epidermal regeneration matrices create functional niches that enhance epidermal morphogenesis. Acta Biomater 2013;9:9474-9484.

113. Hu MS, Maan ZN, Wu J-C, et al. Tissue engineering and regenerative repair in wound healing. Ann Biomed Eng 2014;42:1494-1507.

114. Stewart GA, Lowrey JA, Wakelin SJ, et al. Sonic hedgehog signaling modulates activation of and cytokine production by human peripheral $\mathrm{CD} 4^{+} \mathrm{T}$ cells. J Immunol 2002;169:5451.

115. Fitzpatrick LE, Lisovsky A, Sefton MV. The expression of sonic hedgehog in diabetic wounds following treatment with poly/methacrylic acidco-methyl methacrylate) beads. Biomaterials 2012;33:5297-5307.

116. Moura LI, Dias AM, Leal EC, Carvalho L, de Sousa HC, Carvalho E. Chitosan-based dressings loaded with neurotensin-an efficient strategy to improve early diabetic wound healing. Acta Biomater 2014;10:843-857.

117. Sandri G, Bonferoni MC, Ferrari F, et al. Montmorillonite-chitosan-silver sulfadiazine nanocomposites for topical treatment of chronic skin lesions: in vitro biocompatibility, antibacterial efficacy and gap closure cell motility properties. Carbohydr Polym 2014;102:970-977.

118. Mori M, Rossi S, Ferrari F, et al. Sponge-like dressings based on the association of chitosan and sericin for the treatment of chronic skin ulcers. I. Design of experiments-assisted development. J Pharm Sci 2016;105:1180-1187.

119. Levengood SL, Erickson AE, Chang FC, Zhang M. Chitosan-poly(caprolactone) nanofibers for skin repair. J Mater Chem B Mater Biol Med 2017;5: 1822-1833.

120. Rozman P, Bolta Z. Use of platelet growth factors in treating wounds and soft-tissue injuries. Acta Dermatovenerol Alp Pannonica Adriat 2007; 16:156-165.

121. Keane TJ, Swinehart IT, Badylak SF. Methods of tissue decellularization used for preparation of biologic scaffolds and in vivo relevance. Methods 2015:84:25-34

122. Badylak SF, Valentin JE, Ravindra AK, McCabe GP, Stewart-Akers AM. Macrophage phenotype as a determinant of biologic scaffold remodeling. Tissue Eng Part A 2008;14:1835-1842.

123. Huleihel L, Hussey GS, Naranjo JD, et al. Matrixbound nanovesicles within ECM bioscaffolds. Sci Adv 2016;2:e1600502.

124. Smiell JM, Treadwell T, Hahn HD, Hermans MH. Real-world experience with a decellularized dehydrated human amniotic membrane allograft. Wounds 2015;27:158-169.

125. Zelen C, Serena T, Fetterolf D. Dehydrated human amnion/chorion membrane allografts in patients with chronic diabetic foot ulcers: a longterm follow-up study. Wound Med 2014;4:1-4.

126. Forbes J, Fetterolf DE. Dehydrated amniotic membrane allografts for the treatment of chronic wounds: a case series. J Wound Care 2012;21: 290, 292, 294-296.

127. Sheikh $E$, Sheikh $E$, Fetterolf D. Use of dehydrated human amniotic membrane allografts to promote healing in patients with refractory non healing wounds. Int Wound J 2013;11:711-717.

128. Koob TJ, Rennert R, Zabek N, et al. Biological properties of dehydrated human amnion/chorion composite graft: implications for chronic wound healing. Int Wound J 2013;10:493-500.

129. Maan ZN, Rennert RC, Koob TJ, Januszyk M, Li WW, Gurtner GC. Cell recruitment by amnion chorion grafts promotes neovascularization. J Surg Res 2015;193:953-962.

130. Gallagher KA, Liu ZJ, Xiao M, et al. Diabetic impairments in NO-mediated endothelial progenitor cell mobilization and homing are reversed by hyperoxia and SDF-1 alpha. J Clin Invest 2007; 117:1249-1259.

131. Mirza RE, Fang MM, Ennis WJ, Koh TJ. Blocking interleukin-1 beta induces a healing-associated wound macrophage phenotype and improves healing in type 2 diabetes. Diabetes 2013;62: 2579-2587.

132. Yan $\mathrm{C}$, Gao N, Sun $\mathrm{H}$, et al. Targeting imbalance between IL-1 beta and IL-1 receptor antagonist ameliorates delayed epithelium wound healing in diabetic mouse corneas. Am J Pathol 2016; 186:1466-1480.

133. Ashcroft GS, Jeong MJ, Ashworth JJ, et al. Tumor necrosis factor-alpha (TNF-alpha) is a therapeutic target for impaired cutaneous wound healing. Wound Repair Regen 2012;20:38-49.

134. Olekson MA, Faulknor R, Bandekar A, Sempkowski M, Hsia HC, Berthiaume F. SDF-1 liposomes promote sustained cell proliferation in mouse diabetic wounds. Wound Repair Regen 2015;23:711-723.

135. Fang Y, Shen J, Yao M, Beagley KW, Hambly BD, Bao S. Granulocyte-macrophage colony-stimulating factor enhances wound healing in diabetes via upregulation of proinflammatory cytokines. $\mathrm{Br} \mathrm{J}$ Dermatol 2010;162:478-486.

136. Jaschke E, Zabernigg A, Gattringer C. Recombinant human granulocyte-macrophage colonystimulating factor applied locally in low doses enhances healing and prevents recurrence of chronic venous ulcers. Int J Dermatol 1999:38: 380-386.

137. Da Costa RM, Ribeiro Jesus FM, Aniceto C Mendes M. Randomized, double-blind, placebocontrolled, dose-ranging study of granulocytemacrophage colony stimulating factor in patients with chronic venous leg ulcers. Wound Repair Regen 1999;7:17-25.

138. Tursen U, Api H, Kaya TI, Cinel L, Ikizoglu G. Rapid healing of chronic leg ulcers during perilesional injections of granulocyte-macrophage colony-stimulating factor therapy in a patient with cutaneous polyarteritis nodosa. J Eur Acad Dermatol Venereol 2006;20:1341-1343.

139. Siddiqui FH, Mokhashi MH, Boathman A. Recombinant granulocyte-macrophage colonystimulating factor in the treatment of indolent ulcers with Klippel-Trenaunay-Weber syndrome: a case report. J Pediatr Surg 2007;42:558-560.

140. Huang G, Sun T, Zhang L, et al. Combined application of alginate dressing and human granulocyte-macrophage colony stimulating factor promotes healing in refractory chronic skin ulcers. Exp Ther Med 2014;7:1772-1776.

141. Avitabile $S$, Odorisio T, Madonna $S$, et al. Interleukin-22 promotes wound repair in diabetes by improving keratinocyte pro-healing functions. J Invest Dermatol 2015;135:2862-2870.

142. Carvalho V, Castanheira P, Faria T0, et al. Biological activity of heterologous murine interleukin-10 and preliminary studies on the use of a dextrin nanogel as a delivery system. Int $\mathrm{J}$ Pharm 2010;400:234-242.

143. Braat H, Peppelenbosch MP, Hommes DW. Interleukin-10-based therapy for inflammatory bowel disease. Expert Opin Biol Ther 2003;3: 725-731.

144. Deiters U, Barsig J, Tawil B, Muhlradt PF. The macrophage-activating lipopeptide-2 accelerates wound healing in diabetic mice. Exp Dermatol 2004;13:731-739.

145. Deiters U, Mühlradt PF. Mycoplasmal lipopeptide MALP-2 induces the chemoattractant proteins macrophage inflammatory protein 1alpha (MIP1alpha), monocyte chemoattractant protein 1, and MIP-2 and promotes leukocyte infiltration in mice. Infect Immun 1999;67:3390-3398.

146. Spiller KL, Nassiri S, Witherel CE, et al. Sequential delivery of immunomodulatory cytokines to facilitate the M1-to-M2 transition of macrophages and enhance vascularization of bone scaffolds. Biomaterials 2015;37:194-207.

147. Alvarez MM, Liu JC, Trujillo-de Santiago G, et al. Delivery strategies to control inflammatory response: modulating M1-M2 polarization in tis- 
sue engineering applications. J Control Release 2016:240:349-363.

148. Ishida $Y$, Kondo T, Takayasu T, Iwakura $Y$, Mukaida N. The essential involvement of crosstalk between IFN-gamma and TGF-beta in the skin wound-healing process. J Immunol 2004 172:1848-1855.

149. Yager DR, Chen SM, Ward SI, Olutoye 00 , Diegelmann RF, Kelman Cohen I. Ability of chronic wound fluids to degrade peptide growth factors is associated with increased levels of elastase activity and diminished levels of proteinase inhibitors. Wound Repair Regen 1997;5: 23-32.

150. Gao M, Nguyen TT, Suckow MA, et al. Acceleration of diabetic wound healing using a nove protease-anti-protease combination therapy Proc Natl Acad Sci U S A 2015:112:1522615231.

151. Ovington LG. Advances in wound dressings. Clin Dermatol 2007;25:33-38.

152. Wright JB, Lam K, Buret AG, Olson ME, Burrell RE. Early healing events in a porcine model of contaminated wounds: effects of nanocrystalline silver on matrix metalloproteinases, cell apoptosis, and healing. Wound Repair Regen 2002;10:141-151.

153. Forlee M, Rossington A, Searle R. A prospective, open, multicentre study to evaluate a new gelling fibre dressing containing silver in the management of venous leg ulcers. Int Wound J 2014 11:438-445.

154. Edwards JV, Howley P, Davis R, Mashchak A, Goheen SC. Protease inhibition by oleic acid transfer from chronic wound dressings to albumin. Int J Pharm 2007;340:42-51.

155. Roy S, Sen CK. MiRNA in innate immune responses: novel players in wound inflammation. Physiol Genomics 2011:43:557-565

156. Madhyastha $R$, Madhyastha $H$, Nakajima $Y$, Omura $\mathrm{S}$, Maruyama M. MicroRNA signature in diabetic wound healing: promotive role of miR21 in fibroblast migration. Int Wound J 2012;9: 355-361.

157. Jin Y, Tymen SD, Chen D, et al. MicroRNA-99 family targets AKT/mTOR signaling pathway in dermal wound healing. PLoS One 2013;8:e64434.

158. Li D, Wang A, Liu X, et al. MicroRNA-132 enhances transition from inflammation to proliferation during wound healing. J Clin Invest 2015; 125:3008-3026.

159. Abu-Eid R, Samara RN, Ozbun L, et al. Selective inhibition of regulatory $T$ cells by targeting the PI3K-Akt pathway. Cancer Immunol Res 2014;2: 1080-1089.

160. Xie S, Chen M, Yan B, He X, Chen X, Li D. Identification of a role for the PI3K/AKT/mTOR signaling pathway in innate immune cells. PLoS One 2014;9:e94496.

161. Li J, Kooger R, He M, Xiao X, Zheng L, Zhang Y. A supramolecular hydrogel as a carrier to delive
microRNA into the encapsulated cells. Chem Commun (Camb) 2014:50:3722-3724.

162. Tao SC, Guo SC, Li M, Ke OF, Guo YP, Zhang CO. Chitosan wound dressings incorporating exosomes derived from microRNA-126-overexpressing synovium mesenchymal stem cells provide sustained release of exosomes and heal full-thickness skin defects in a diabetic rat model. Stem Cells Transl Med 2016:6:736-747.

163. Rabbani PS, Zhou A, Borab ZM, et al. Nove lipoproteoplex delivers Keap1 siRNA based gene therapy to accelerate diabetic wound healing Biomaterials 2017;132:1-15.

164. Li N, Luo HC, Ren M, et al. Efficiency and safety of beta-CD-(D3)7 as siRNA carrier for decreasing matrix metalloproteinase- 9 expression and improving wound healing in diabetic rats. ACS Appl Mater Interfaces 2017:9:17417-17426.

165. Luo HC, Li N, Yan L, et al. Comparison of the cellular transport mechanism of cationic, starshaped polymers and liposomes in HaCat cells. Int J Nanomedicine 2017;12:1085-1096.

166. van der Pol E, Boing AN, Harrison P, Sturk A Nieuwland R. Classification, functions, and clinical relevance of extracellular vesicles. Pharmacol Rev 2012;64:676-705.

167. Geiger A, Walker A, Nissen E. Human fibrocytederived exosomes accelerate wound healing in genetically diabetic mice. Biochem Biophys Res Commun 2015;467:303-309.

168. Ti D, Hao H, Tong C, et al. LPS-preconditioned mesenchymal stromal cells modify macrophage polarization for resolution of chronic inflammation via exosome-shuttled let-7b. J Transl Med 2015;13:308

169. Rahimnejad M, Derakhshanfar S, Zhong W Biomaterials and tissue engineering for scar management in wound care. Burns Trauma 2017:5:4.

170. Maggini J, Mirkin G, Bognanni I, et al. Mouse bone marrow-derived mesenchymal stromal cells turn activated macrophages into a regulatory-like profile. PLoS One 2010;5

171. Jackson WM, Nestl LJ, Tuan RS. Mesenchymal stem cell therapy for attenuation of scar formation during wound healing. Stem Cell Res Ther 2012;3:20-28.

172. Bertozzi N, Simonacci F, Grieco MP, Grignaffini E, Raposio E. The biological and clinical basis for the use of adipose-derived stem cells in the field of wound healing. Ann Med Surg 2017;20:41-48.

173. De Buys Roessingh AS, Hohlfeld J, Scaletta C et al. Development, characterization, and use of a fetal skin cell bank for tissue engineering in wound healing. Cell Transplant 2006;15: 823-834.

174. Sridharan R, Cameron AR, Kelly DJ, Kearney CJ, 0 'Brien FJ. Biomaterial based modulation of macrophage polarization: a review and suggested design principles. Mater Today 2015;18: 313-325.
175. Cash JL, Bass MD, Campbell J, Barnes M, Kubes P. Martin P. Resolution mediator Chemerin15 reprograms the wound microenvironment to promote repair and reduce scarring. Curr Biol 2014:24:1406-1414.

176. Soares de Souza K, Cantaurti TA, Azevedo GM et al. Improved cutaneous wound healing after intraperitoneal injection of alpha-melanocytestimulating hormone. Exp Dermatol 2015;24 198-203.

177. Taylor AW, Lee DJ. The alpha-melanocyte stimulating hormone induces conversion of effector T cells into Treg cells. J Transplant 2011; 2011:246856.

178. Zhu X, Sun Y, Mu X, et al. Phospholipase CE deficiency delays the early stage of cutaneous wound healing and attenuates scar formation in mice. Biochem Biophys Res Commun 2017;484:144-151.

179. Ding J, Tredget EE. The role of chemokines in fibrotic wound healing. Adv Wound Care 2015; 4:673-686.

180. Jeong W, Yang CE, Roh TS, Kim JH, Lee JH, Lee WJ. Scar prevention and enhanced wound healing induced by polydeoxyribonucleotide in a rat incisional wound-healing model. Int $\mathrm{J} \mathrm{Mol}$ Sci 2017;18:pii: E1698.

181. Cantaruti TA, Costa RA, Soares de Souza K, Vaz NM, Carvalho CR. Indirect effects of immunological tolerance to a regular dietary protein reduce cutaneous scar formation. Immunology 2017;151:314-323.

182. Zheng Z, Zhang X, Dang C, et al. Fibromodulin is essential for fetal-type scarless cutaneous wound healing. Am J Pathol 2016;186:28242832

183. Hall BE, Wankhade UD, Konkel JE, et al. Transforming growth factor- $\beta 3$ (TGF- $\beta 3$ ) knock-in ameliorates inflammation due to TGF- $\beta 1$ deficiency while promoting glucose tolerance. J Biol Chem 2013;288:32074-32092.

184. Yoshii A, Kitahara S, Ueta H, Matsuno K, Ezaki $T$. Role of uterine contraction in regeneration of the murine postpartum endometrium. Biol Reprod 2014;91:32.

185. Tziotzios C, Profyris C, Sterling J. Cutaneous scarring: pathophysiology, molecular mechanisms, and scar reduction therapeutics. J Am Acad Dermatol 2012:66:13-24.

186. Poon R, Hong H, Wei X, Pan J, Alman BA. A high throughput screen identifies Nefopam as targeting cell proliferation in $\beta$-catenin driven neoplastic and reactive fibroproliferative disorders. PLoS One 2012:7:e37940.

187. Ishida Y, Gao JL, Murphy PM. Chemokine receptor CXC3CR1 mediates skin wound healing by promoting macrophage and fibroblast accumulation and function. J Immunol 2008;180:569-579.

188. Huen AC, Wells $A$. The beginning of the end CXCR3 signaling in late stage wound healing. Adv Wound Care 2012:1:244-248. 
189. Martino MM, Briquez PS, Güç E, et al. Growth factors engineered for super-affinity to the extracellular matrix enhancing tissue healing. Science 2014;343:885-888.

190. Kamaly N, Yameen B, Wu J, Farokhzad OC. Degradable controlled-release polymers and polymeric nanoparticles: mechanisms of controlling drug release. Chem Rev 2016;116: 2602-2663.

\footnotetext{
Abbreviations and Acronyms

$\alpha \mathrm{MSH}=$ alpha-melanocyte-stimulating hormone

ASC $=$ adipose-derived stem cell

$\mathrm{C} 15=$ Chemerin 15

$\mathrm{CXCL}=\mathrm{C}-\mathrm{X}-\mathrm{C}$ chemokine ligand

CXCR2 $=$ C-X-C motif chemokine receptor 2

DDHAM $=$ dehydrated human amniotic membrane

DFU $=$ diabetic foot ulcer

DSCG $=$ disodium cromoglicate

$\mathrm{ECM}=$ extracellular matrix
}

$\begin{aligned} & \mathrm{EV}=\text { extracellular vesicle } \\ & \mathrm{FBGC}=\text { foreign body giant cell } \\ & \mathrm{FGF}=\text { fibroblast growth factor } \\ & \mathrm{GM}-\mathrm{CSF}=\text { granulocyte macrophage } \\ & \text { colony-stimulating factor } \\ & \mathrm{HA}=\text { hyaluronic acid } \\ & \mathrm{HMGB}=\text { high-motility group box } \\ & \mathrm{HSC}=\text { hematopoietic stem cell } \\ & \mathrm{HT}=\text { hypertrophic } \\ & \mathrm{IFN}=\text { interferon } \\ & \mathrm{IGF}=\text { insulin-like growth factor } \\ & \mathrm{IL}=\text { interleukin } \\ & \mathrm{IL}-1 \mathrm{Ra}=\text { IL-1 receptor antagonist } \\ & \mathrm{LC}=\text { Langerhans cells } \\ & \mathrm{M} 6 \mathrm{P}=\text { mannose-6-phosphate } \\ & \mathrm{MALP}=\text { macrophage-activating lipopeptide } \\ & \mathrm{MBV}=\text { matrix-bound nanovesicle } \\ & \mathrm{MCP}=\text { macrophage chemoattractant protein } \\ & \mathrm{MIP}=\text { macrophage inflammatory protein } \\ & \mathrm{MMP}=\text { matrix metalloproteinase } \\ & \mathrm{MSC}=\text { mesenchymal stem cell } \\ &\end{aligned}$

$\begin{aligned} \text { NET } & =\text { neutrophil extracellular trap } \\ \text { NT } & =\text { normotrophic } \\ \text { PDGF } & =\text { platelet-derived growth factor } \\ \text { PDRN } & =\text { polydeoxyribonucleotide } \\ \text { PGE2 } & =\text { prostaglandin E2 } \\ \text { PLC } \varepsilon & =\text { phospholipase } \mathrm{C} \varepsilon \\ \mathrm{PRP} & =\text { platelet-rich plasma } \\ \mathrm{ROS} & =\text { reactive oxygen species } \\ \text { SDF } & =\text { stromal cell-derived factor } \\ \text { Shh } & =\text { sonic hedgehog signaling } \\ \text { siRNA } & =\text { small interfering RNA } \\ \text { STAT3 } & =\text { signal transducer and activator } \\ \text { TCR } & =\text { of cell receptor } \\ \text { TGF } & =\text { transforming growth factor } \\ \text { TH1 } & =\text { type } 1 \text { Thelper } \\ \text { TIMP } & =\text { tissue inhibitor of matrix } \\ \text { TNF } & =\text { metalloproteinase } \\ \text { Treg } & =\text { regulatory T cells } \\ \text { VEGF } & =\text { vascular endothelial growth factor }\end{aligned}$

